\title{
Wave Forcing of the Quasi-Biennial Oscillation in the Max Planck Institute Earth System Model
}

\author{
ThOMAS R. Krismer AND MARco A. GiorgetTA \\ Max Planck Institute for Meteorology, Hamburg, Germany
}

(Manuscript received 9 October 2013, in final form 3 February 2014)

\begin{abstract}
This study investigates the resolved wave forcing of the quasi-biennial oscillation (QBO) in the Max Planck Institute Earth System Model truncated at T63 with 95 vertical levels. The model, which parameterizes unresolved gravity waves, internally generates a QBO. The resolved waves contribute up to $50 \%$ and $30 \%$ to the total wave forcing (resolved plus parameterized) of the QBO westerly and easterly jet, respectively, mostly owing to waves with zonal wavenumbers lower than 20 and frequencies lower than $0.5 \mathrm{cpd}$. At higher frequencies and wavenumbers, the model underestimates the strength of the tropospheric wave sources when compared to Tropical Rainfall Measuring Mission (TRMM) observations and applies strong horizontal diffusion, which explains the shortage of wave momentum at these scales (relative to recent studies based on high-resolution models). The study further relates the vertical structure of equatorial Kelvin waves, which contribute most to the transport and deposition of westerly wave momentum, to their radiative dissipation and compares the role of longwave radiation and horizontal diffusion in the dissipation of the resolved waves in general. The Kelvin waves adjust their vertical wavelength according to their intrinsic phase speed and are efficiently damped by longwave radiation within westerly flow, where the vertical wavelength strongly decreases. Waves with zonal wavenumbers larger than 10 , however, are mostly damped by horizontal diffusion. The latitudinal distribution of the resolved wave forcing reflects the latitudinal structure of the waves and is asymmetric with respect to the equator.
\end{abstract}

\section{Introduction}

The variability of the general circulation in the tropical stratosphere is dominated by the wave-driven quasibiennial oscillation (QBO) (Baldwin et al. 2001). The QBO most clearly manifests itself in easterly and westerly jets that originate in the upper stratosphere, propagate downward to the vicinity of the tropopause, and oscillate with a period ranging from 22 to 34 months (Baldwin et al. 2001).

Lindzen and Holton (1968) and Holton and Lindzen (1972) presented and refined the first plausible theoretical explanation of the QBO. They argued that the QBO is driven by vertically propagating atmospheric waves that deposit easterly and westerly momentum due

D Denotes Open Access content.

Corresponding author address: Thomas R. Krismer, Max Planck Institute for Meteorology, Bundesstr. 53, 20146 Hamburg, Germany. E-mail: thomas.krismer@mpimet.mpg.de to radiative attenuation and wave breaking in the vicinity of the waves' critical levels, where the phase speed of a wave is close to the background wind speed. Waves that deposit their wave momentum around the zero wind line between easterly and westerly jets drive the zero wind line downward, toward the wave sources. Dunkerton (1991) showed that the generally upward-directed residual vertical motion in the tropics tends to advect the QBO jets upward and, hence, works against their downward propagation.

After a number of observational and modeling studies, it is now established that a continuous spectrum of large-scale equatorial waves and small-scale gravity waves transport the momentum necessary to propagate the QBO jets against the resistance of the tropical upwelling (Sato and Dunkerton 1997; Canziani and Holton 1998; Ern and Preusse 2009a,b; Kawatani et al. 2010a; Evan et al. 2012). The waves are mostly triggered by tropical convection (Fritts and Alexander 2003 and references therein).

The QBO influences the stratospheric circulation in the extratropics (Holton and Tan 1980; Anstey 
and Shepherd 2014; Watson and Gray 2014) and the distribution of trace gases in the stratosphere (Mote et al. 1996; Schoeberl et al. 2008; Punge and Giorgetta 2008). Further, owing to the wide range of scales, from planetary-scale Matsuno-type equatorial waves (Matsuno 1966) to small-scale gravity waves, it is not yet possible to close the stratospheric momentum balance based on observations. Thus, to cover the full range of stratospheric variability and to study stratospheric dynamics, it is desirable to internally generate the QBO in general circulation models (GCMs). However, the number of GCMs capable of simulating a QBO is still limited.

To internally generate a QBO-like oscillation comparable to observations, GCMs need to transport sufficient wave momentum into the stratosphere, either by applying some sort of gravity wave parameterization scheme to substitute unresolved waves (Scaife et al. 2000; Giorgetta et al. 2002; Orr et al. 2010; Xue et al. 2012) or by resolving the relevant wave spectrum using high horizontal resolution (Kawatani et al. 2010a; Evan et al. 2012). High vertical resolution is necessary to accurately simulate the waves' response to the changing background flow (Giorgetta et al. 2006).

Giorgetta et al. (2006) presented a climatology of the forcing of the QBO based on an operational GCM, showing that parameterized small-scale gravity waves are as important in forcing the QBO as the resolved waves with zonal wavenumbers up to 42 . The spectral distribution of the QBO wave forcing has been presented by Kawatani et al. (2010a) and Evan et al. (2012); however, because of the computational costs of their high-resolution experiments, their results covered only two quasi-biennial cycles or even months. This study presents a detailed spectral analysis of the resolved wave forcing of the QBO as done by Kawatani et al. (2010a) and Evan et al. (2012), but based on a 500-yr-long simulation conducted with the operational Max Planck Institute Earth System Model (MPI-ESM) truncated at T63 and, thus, continues the work of Giorgetta et al. (2006). The study therefore gives a reference for the QBO forcing in the current generation of GCMs with relatively course resolution.

In earlier studies, the wave-mean flow interactions driving the QBO have been discussed indirectly based on the divergence of the wave momentum flux in regions of strong vertical shear associated with the QBO jets. Ern and Preusse (2009b) and Yang et al. (2011) illustrated the underlying wave attenuation by the loss of spectral power of filtered wave modes with altitude. However, literature lacks the explicit discussion of the dynamical and physical mechanisms by which GCMs dissipate resolved waves-diffusive and radiative wave damping — which are covered in theoretical work (Fels
1982; Zhu 1993), idealized in model studies (Holton and Lindzen 1972; Ern et al. 2009a), and implemented in gravity wave parameterization schemes. With respect to increased efforts in understanding the spread of QBO features among models in recent years, understanding these fundamental wave mechanics is crucial. It is one of the main goals of this study to show how longwave radiation and diffusion damp different parts of the resolved wave spectrum in MPI-ESM and, thus, lead to the acceleration of the mean flow and the generation of a QBO-like oscillation. This includes the modulation of the waves' vertical structure during opposite QBO phases, the implications for the longwave radiative damping processes, and a comparison of radiative and diffusive wave damping for different parts of the wave spectrum.

The study is structured as follows. Sections 2 and 3 give a short description of the applied model and the simulated QBO. Section 4 validates the spectra of tropical precipitation as a proxy for the convective wave sources and, thus, contributes to the ongoing discussion about the strength of tropospheric wave sources necessary to force the QBO (Lott et al. 2014). Section 5 describes the filtering of the stratospheric wave field by the QBO jets and the underlying wave dissipation processes. Section 6 presents profiles of the wave momentum flux and the wave-momentum deposition during opposite QBO phases, which are extended to latitudinal cross sections and to the whole quasi-biennial cycle. Section 7 presents the total momentum balance including the parameterized wave forcing and advection.

\section{Model description}

This work makes use of the Max Planck Institute Earth System Model (Giorgetta et al. 2013) in the mixed-resolution (MR) configuration, which consists of the ECHAM6 atmospheric GCM (Stevens et al. 2013), the Jena Scheme for Biosphere-Atmosphere Coupling in Hamburg (JSBACH) land vegetation model (Raddatz et al. 2007), and the Max Planck Institute Ocean Model (MPIOM) GCM (Jungclaus et al. 2013) including the Hamburg Oceanic Carbon Cycle (HAMOCC) ocean biogeochemistry model (for brevity, the generic name MPI-ESM is used in the following text). The MR configuration designates the resolution of atmosphere and ocean GCMs, where the ocean model makes use of a tripolar grid with a nominal resolution of $0.4^{\circ}$. The vertical grid has $40 z$ levels. In the MR configuration, the atmospheric component ECHAM6 uses a spectral truncation at wavenumber 63 and an associated Gaussian grid of approximately $1.9^{\circ}$ resolution in longitude and latitude. The vertical grid has 95 hybrid sigma pressure levels resolving the atmosphere from the 
surface up to the center of the uppermost layer at $0.01 \mathrm{hPa}$. The top-of-the-model pressure is defined as $0 \mathrm{hPa}$. This grid has a nearly constant vertical resolution of $700 \mathrm{~m}$ from the upper troposphere to the middle stratosphere, and the resolution is better than $1 \mathrm{~km}$ at the stratopause. Thus the vertical grid is overall comparable to that used by Giorgetta et al. (2006) with respect to the vertical resolution in the QBO domain. MPI-ESM is capable of internally generating a QBO with a realistic period, vertical extent, and seasonal modulations, but overestimates the QBO amplitude (Krismer et al. 2013).

The parameterization of convection, which is known to influence the resolved wave field (Horinouchi et al. 2003), follows the Tiedtke-Nordeng scheme (Möbis and Stevens 2012). ECHAM6 includes the Hines parameterization for nonorographic gravity waves (Hines 1997a,b). The source spectrum of the Hines parameterization follows the MAECHAM5 standard setting (Manzini and McFarlane 1998; Manzini et al. 2006). However, the otherwise constant wave-induced horizontal wind perturbations (rms winds) increase linearly from 1 to $1.2 \mathrm{~m} \mathrm{~s}^{-1}$ over $10^{\circ}-5^{\circ} \mathrm{N}\left(10^{\circ}-5^{\circ} \mathrm{S}\right)$. From $5^{\circ} \mathrm{N}$ to $5^{\circ} \mathrm{S}$, the rms winds are constant at $1.2 \mathrm{~m} \mathrm{~s}^{-1}$. The modification of the source spectrum of the Hines parameterization was necessary to obtain a realistic QBO period in MPI-ESM, where ECHAM6 is coupled to an ocean model. Because of nonlinearities, the $20 \%$ increase of the rms winds leads to a 4-times-larger parameterized wave drag at the zero wind lines associated with the onset of the QBO jets. Given the lack of observational constraints on tropical gravity waves and considering that the mostly convective nonorographic wave sources, which are represented by the Hines scheme, are more abundant in the tropics than in the extratropics, such an enhancement seems to be justified. Giorgetta et al. (2006) showed that increasing the rms winds in MAECHAM5 by $10 \%$ strengthens the QBO westerly jets and reduces the period. With an idealized one-dimensional model, Scaife et al. (2000) showed that the QBO period generally decreases with increasing parameterized wave sources. The prescribed gravity wave sources are constant in time and the wave source is at $700 \mathrm{hPa}$.

MPI-ESM has been used for many phase 5 of the Coupled Model Intercomparison Project (CMIP5) simulations (Taylor et al. 2012). A number of recent publications based on MPI-ESM and its components review the dynamics of the middle atmosphere (Schmidt et al. 2012), the seasonal modulation of the quasi-biennial oscillation (Krismer et al. 2013), the stratospheretroposphere coupling (Tomassini et al. 2012), tropical precipitation (Crueger et al. 2013), and model tuning
(Mauritsen et al. 2012) for MPI-ESM. This study makes use of the preindustrial CMIP5 control simulation (piControl), which is forced by 1850 conditions and was integrated over 1000 years (Giorgetta et al. 2012). Most of this study refers to the first 30 years of the piControl simulation, which is the only period where the parameterized gravity wave drag, the longwave radiative temperature tendency, and the horizontal and vertical diffusion have been stored. The first 30 years analyzed in section 5 include 14 quasi-biennial cycles. The first 500 simulated years, which are analyzed to discuss the resolved wave drag in section 6, include 209 quasi-biennial cycles.

\section{Mean structure of the QBO}

Figure 1 shows the time-height cross section of the zonal mean zonal wind in the tropical stratosphere over a 15-yr period in the 40-yr European Centre for Medium-Range Weather Forecasts (ECMWF) ReAnalysis (ERA-40) and MPI-ESM. Though ERA-40 seems to have an easterly bias prior to the 1980s (Punge and Giorgetta 2008), it is known to well represent the amplitude and variance of the QBO (Baldwin 2005). In Fig. 1, the QBO clearly shows in the oscillation of westerly and easterly jets between 5 and $100 \mathrm{hPa}$. In the displayed 15 years, the reanalysis and the model complete about six quasi-biennial cycles. Over the whole 500 years of the model simulation, the average QBO period in MPI-ESM is 28.7 months, which corresponds well to observations (Baldwin et al. 2001). MPI-ESM covers the regular downward propagation rates of the QBO westerly jets as well as the stalling of the easterly jets below $30 \mathrm{hPa}$. The semiannual oscillation above $5 \mathrm{hPa}$ is stronger in MPI-ESM than in ERA-40. However, consistent with the reanalysis, the semiannual oscillation (SAO) westerly jets penetrate to deeper altitudes in months when the QBO westerly jet is at low altitudes and comparatively weak. In ERA-40, the QBO jets are strongest at $20 \mathrm{hPa}$, where the QBO easterly and westerly jets exceed -30 and $+10 \mathrm{~m} \mathrm{~s}^{-1}$, respectively (Fig. 1a). In MPI-ESM, the QBO jets reach their maximal strength higher than in ERA-40 at $10 \mathrm{hPa}$ (Fig. 1b). The QBO westerly jet in MPI-ESM is about $50 \%$ stronger than in observations and exceeds $+20 \mathrm{~m} \mathrm{~s}^{-1}$. Above $30 \mathrm{hPa}$, the strength of the QBO easterly jet matches ERA-40; however, it does not penetrate as deep as in the reanalysis dataset. For further comparison of the QBO in MPI-ESM and ERA-40, the reader is referred to Krismer et al. (2013).

Most of this study will focus on the wave-mean flow interactions in MPI-ESM during two phases within a quasi-biennial cycle, which are indicated by thick vertical 
$\bar{u}[\mathrm{~m} / \mathrm{s}], \mathrm{ERA}-40,5 \mathrm{~N}-5 \mathrm{~S}$

a)
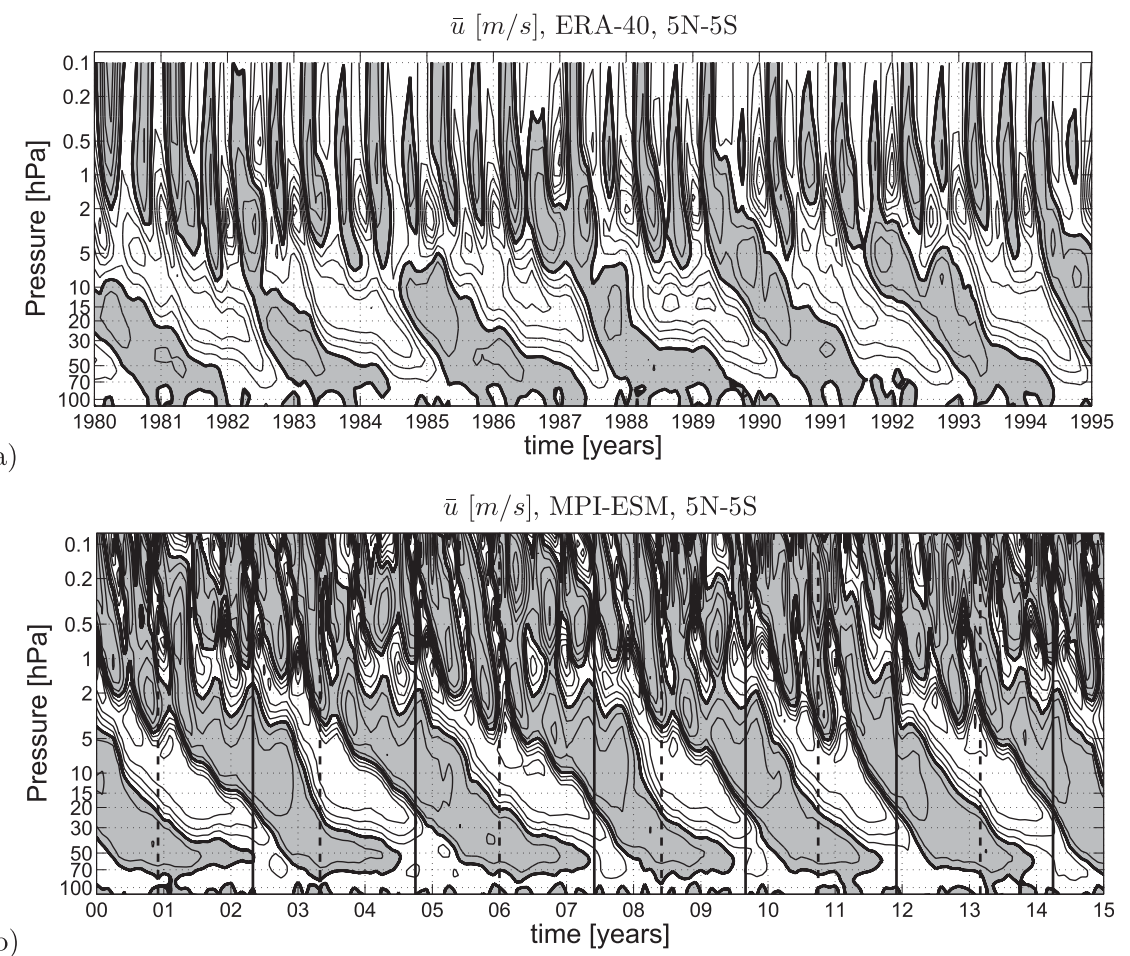

FIG. 1. Time-height cross section of the zonal mean zonal wind in (a) ERA-40 and (b) MPIESM. The contour interval is $10 \mathrm{~m} \mathrm{~s}^{-1}$. Positive wind speeds are shaded in gray. The thick contour indicates the zero wind line. Thick vertical lines in (b) indicate months referred to as QBO westerly (solid lines) and easterly (dashed lines) phases.

lines in Fig. 1b. The phases are defined by first finding a pair of months where the zonal wind at $20 \mathrm{hPa}$ changes its sign. The month where the zonal wind is closer to $0 \mathrm{~m} \mathrm{~s}^{-1}$ is sampled. At $20 \mathrm{hPa}$, such a wind reversal occurs only twice during a quasi-biennial cycle: once when the wind turns from easterly to westerly (solid vertical lines in Fig. 1b) and once when it turns from westerly to easterly (dashed vertical lines in Fig. 1b).

During months with a westerly wind transition at $20 \mathrm{hPa}$, the zonal wind is easterly below $20 \mathrm{hPa}$ and westerly above. These months will be referred to as QBO westerly phase (solid lines in Fig. 1b). Likewise, during months with an easterly wind transition at $20 \mathrm{hPa}$, the zonal wind is westerly below $20 \mathrm{hPa}$ and easterly above (dashed lines in Fig. 1b). These months will be referred to as QBO easterly phase. During the first 30 and the first 500 years of the piControl simulations analyzed here, 14 and 209 phase changes occur, respectively.

\section{Spectral variability of tropical precipitation}

The momentum necessary to drive the QBO is carried by a continuous spectrum of waves (Sato and Dunkerton 1997; Canziani and Holton 1998; Ern and Preusse 2009b,a) that are mostly triggered by latent heat release within convective clouds [see Fritts and Alexander (2003) and references therein]. Tropical precipitation is a widely used proxy for tropical convective activity. Although Lott et al. (2014) found that the intermodel variability of Kelvin and Rossby wave activity at $50 \mathrm{hPa}$ is less dependent on the intermodel variability of the precipitation spectra than anticipated before (Horinouchi et al.2003), this section presents and validates the spectral characteristics of tropical precipitation in MPI-ESM to estimate the strength of tropical wave sources in a way comparable to earlier studies (Kawatani et al. 2010a; Evan et al. 2012). MPI-ESM is validated against the 3B42 dataset from the satellite-based Tropical Rainfall Measuring Mission (TRMM) (Huffman et al. 2007), which covers most of the rainfall events observed with gauge and radar measurements in the Pacific (Huffman et al. 2007) and is more accurate than most other global reanalysis products (Kim and Alexander 2013).

Figure 2a shows the latitudinal distribution of the zonally averaged daily precipitation rates in TRMM and in MPI-ESM in the tropical Pacific between $120^{\circ} \mathrm{E}$ and $90^{\circ} \mathrm{W}$. Here, the TRMM data have been averaged from 1998 to 2008, and an equally long period has been chosen from the MPI-ESM piControl simulation. Both datasets show the highest precipitation rates north and south of 

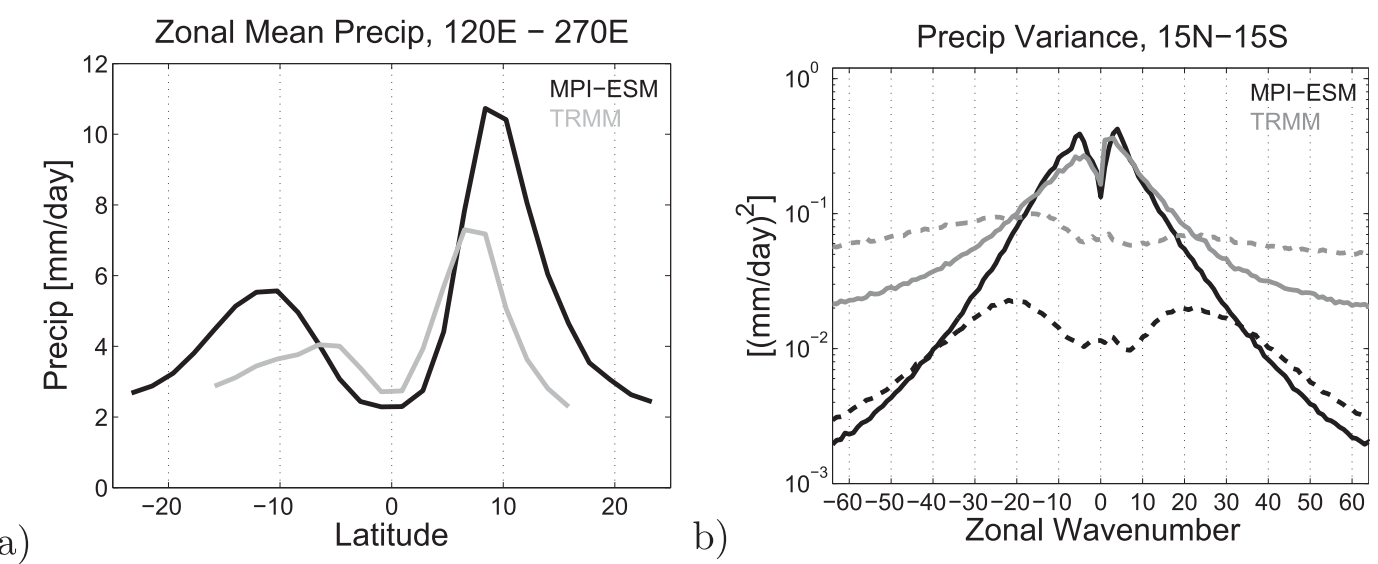

FIG. 2. (a) Latitudinal distribution of zonal mean tropical precipitation $\left(\mathrm{kg} \mathrm{m}^{-2} \mathrm{day}^{-1}\right)$ in the Pacific region in TRMM (gray line, averaged from 1998 to 2008) and MPI-ESM (black line, averaged over the first 11 years of the model run). (b) Precipitation variance $\left[\left(\mathrm{kg} \mathrm{m}^{-2} \mathrm{day}^{-1}\right)^{2}\right]$ in TRMM (gray line) and MPI-ESM (black line), averaged from $15^{\circ} \mathrm{N}$ to $15^{\circ} \mathrm{S}$ as a function of the zonal wavenumber. The variance has been integrated over frequencies ranging from 0 to $0.5 \mathrm{cpd}$ (solid lines) and from 0.5 to $2 \mathrm{cpd}$ (dashed lines). Negative wavenumbers indicate easterly waves.

the equator; however, compared to TRMM, the precipitation rates are generally higher and the peaks are shifted to higher latitudes in MPI-ESM.

To estimate the capability of MPI-ESM to simulate a realistic spectrum of convectively triggered waves, Fig. $2 \mathrm{~b}$ shows the precipitation variance in TRMM and MPIESM as a function of the zonal wavenumber for waves with frequencies between 0 and $0.5 \mathrm{cpd}$ and between 0.5 and $2 \mathrm{cpd}$. Before calculating the spectra, the TRMM data have been interpolated from the original $0.25^{\circ}$ grid to the $1.9^{\circ}$ grid used in MPI-ESM. Only four observations per day have been used $(6,12,18$, and $24 \mathrm{~h})$ to match the sampling rate of the model data. The spectra have been calculated as described by Wheeler and Kiladis (1999). First, the precipitation is partitioned into 128-day-long time windows with an overlap of 75 days, which gives 72 time windows to cover the $11-y r$ period. In every time window, the zonal and temporal means have been subtracted from the data, and each time window has been tapered in time. Following Lin et al. (2006), the data have been averaged from $15^{\circ} \mathrm{S}$ to $15^{\circ} \mathrm{N}$ prior to calculating the wave spectrum. The latitudinal range fully includes the peaks in precipitation in MPIESM around $\pm 10^{\circ}$ (Fig. 2a). The spectral powers are calculated by applying the fast Fourier transform in time and longitude on the precipitation data in each time window and then averaged over all time windows. Figure $2 \mathrm{~b}$ demonstrates that compared to TRMM, MPI-ESM well simulates the precipitation variance at frequencies lower than $0.5 \mathrm{cpd}$ and wavenumbers lower than \pm 20 (zonal wavenumber $\lambda=2000 \mathrm{~km}$ ) but underestimates the variance at wavenumbers larger than \pm 20 and frequencies larger than $0.5 \mathrm{cpd}$.
The organization of the tropical wave field is illustrated by the wavenumber-frequency spectra of the precipitation variance in TRMM and MPI-ESM shown in Fig. 3. The spectra are computed as described for Fig. 2b; however, following Wheeler and Kiladis (1999), the precipitation is decomposed into symmetric and antisymmetric anomalies around the equator before applying the latitudinal average, so that $P(\phi)_{\text {sym }}=[P(\phi)+$ $P(-\phi)] / 2$ and $P(\phi)_{\text {asym }}=[P(\phi)-P(-\phi)] / 2$, where $P$ is the precipitation rate and $\phi$ is the latitude.

Figures $3 \mathrm{a}$ and $3 \mathrm{~d}$ show the sum of the symmetric and antisymmetric wave spectra $P_{\text {sym }}(\omega, k)+P_{\text {asym }}(\omega, k)$ for TRMM and MPI-ESM, where $\omega$ is the frequency and $k$ is the zonal wavenumber. As shown by Kim and Alexander (2013), the precipitation variance in TRMM is red in wavenumber and frequency and clearly organizes along phase speeds of -20 and $+15 \mathrm{~m} \mathrm{~s}^{-1}$ (Fig. 3a). MPI-ESM also shows this organization, although less pronounced than TRMM (Fig. 3d). At frequencies higher than $0.5 \mathrm{cpd}$, the TRMM spectrum has more spectral power at easterly than at westerly waves (negative and positive wavenumbers, respectively) while in MPI-ESM, the spectral powers are more evenly distributed. At wavenumbers smaller than \pm 20 and frequencies lower than $0.2 \mathrm{cpd}$, the precipitation variance in MPI-ESM is larger than in TRMM. However, compared to TRMM, the variance in MPI-ESM decreases much more rapidly with higher wavenumbers and frequencies.

Figures $3 \mathrm{~b}$ and $3 \mathrm{e}$ show the spectra of the symmetric precipitation variance in TRMM and MPI-ESM, respectively, and Figs. $3 \mathrm{c}$ and $3 \mathrm{f}$ show the antisymmetric spectra of both datasets. The contour lines indicate the symmetric and antisymmetric spectral power, while the 


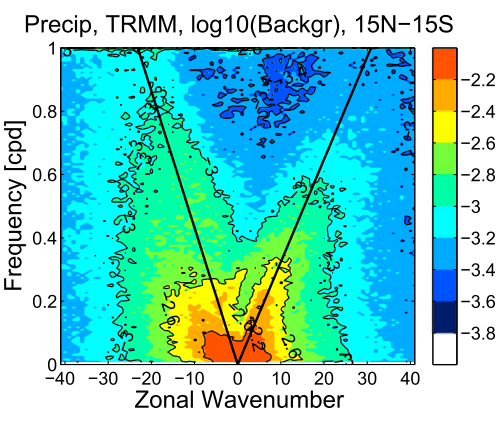

a)

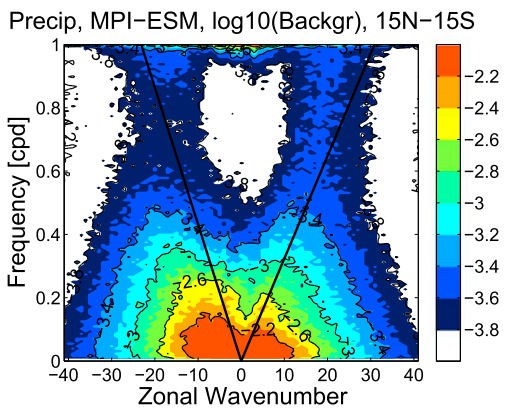

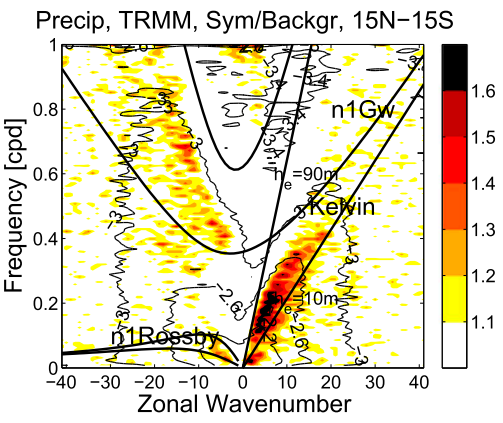

b)

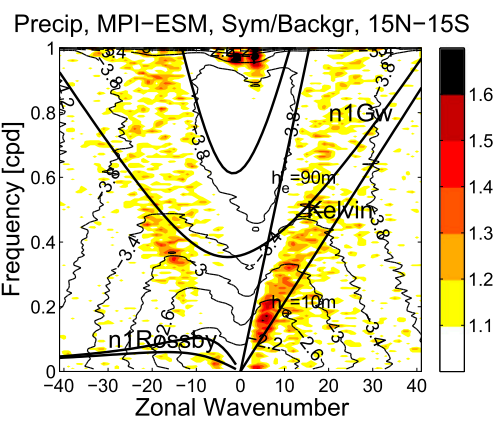

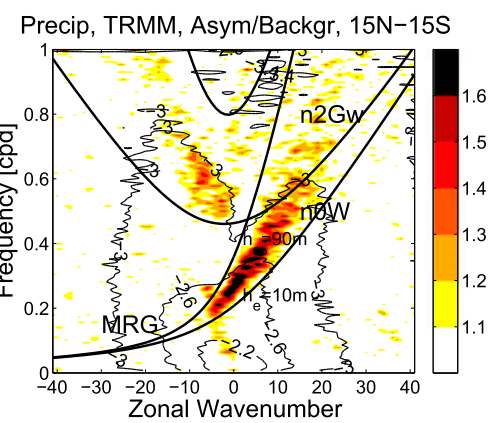

c)

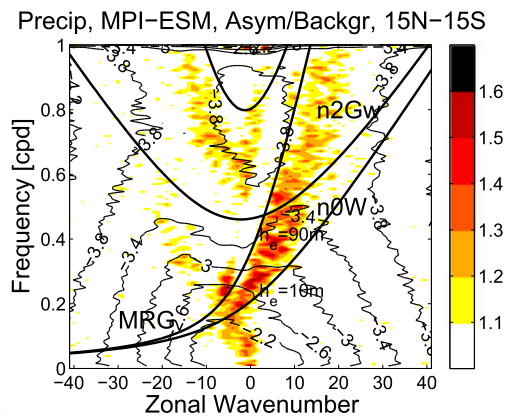

FIG. 3. Latitudinal mean $\left(15^{\circ} \mathrm{N}-15^{\circ} \mathrm{S}\right)$ background, symmetric, and antisymmetric zonal wavenumber-frequency spectra of precipitation variance $\left\{\log \left[\left(\mathrm{kg} \mathrm{m}^{-2} \mathrm{day}^{-1}\right)^{2}\right]\right\}$ in (a)-(c) TRMM and (d)-(f) MPI-ESM. Black lines in (a),(d) are lines of constant phase speed of -20 and $15 \mathrm{~m} \mathrm{~s}^{-1}$. (b),(e) The dispersion lines of symmetric Kelvin waves, easterly Rossby waves, and n1 gravity waves and (c),(f) the antisymmetric mixed Rossby-gravity waves, $\mathrm{n} 0$ westerly waves, and $\mathrm{n} 2$ gravity waves with equivalent depths of 10 and $90 \mathrm{~m}$ are superimposed on the symmetric and antisymmetric spectra, respectively. Negative wavenumbers indicate easterly waves.

shading indicates the ratio of the symmetric and antisymmetric spectra to a background spectrum. The background spectrum is computed by adding the symmetric and antisymmetric wave spectrum and smoothing it with multiple 1-2-1 filters in wavenumber at each frequency (Wheeler and Kiladis 1999). Ratios larger than 1.1 indicate organized convection (Wheeler and Kiladis 1999). The dispersion lines of Matsuno-type equatorial waves (Matsuno 1966), which are the preferred modes of variability in the tropics (Wheeler and Kiladis 1999; Kiladis et al. 2009), are superimposed on the plots. In TRMM and MPI-ESM, the shapes of the symmetric and antisymmetric spectra do not differ much from the sum of both spectra (cf. Fig. 3a to Figs. 3b,c and Fig. 3d to Figs. 3e,f). However, in both datasets, the ratios of the symmetric and antisymmetric spectra to the background spectrum show clear signals of symmetric Kelvin waves and $\mathrm{n} 1$ gravity waves (Figs. $3 \mathrm{~b}, \mathrm{e})$ and antisymmetric mixed Rossby-gravity waves, $\mathrm{n} 0$ westerly waves, and $\mathrm{n} 2$ gravity waves (Figs. $3 \mathrm{c}, \mathrm{f}$ ) with equivalent depths $h_{e}$ between 10 and $90 \mathrm{~m}$ [the notation $\mathrm{n} 0, \mathrm{n} 1$, and $\mathrm{n} 2$ gravity waves refers to solutions for equatorial waves in Matsuno (1966) with the order $n=0, n=1$, and $n=2$ ]. In TRMM, the ratios of Kelvin and mixed Rossby-gravity (MRG) waves are slightly higher than in MPI-ESM, which demonstrates the higher grade of organization in TRMM.

\section{The stratospheric wave field}

\section{a. Wavenumber-frequency spectra}

The tropical precipitation discussed above excites vertically propagating waves, which carry the zonal momentum necessary to force the QBO. In the following, the wavenumber-frequency spectra of temperature at various altitudes during the QBO westerly and easterly phase are discussed, as Ern and Preusse (2009b) and Yang et al. (2012) showed that waves filtered by the QBO jets lose spectral power with altitude and, thus, identified the waves potentially contributing to the $\mathrm{QBO}$ forcing. It shall be put upfront that the ground-based frequency of a convectively triggered wave is mostly defined by the interplay of the tropospheric heating profile associated with the convective event and the background wind at the source level [see Fritts and Alexander (2003) and references therein]. Given slowly varying background winds in the stratosphere, the wave's groundbased frequency does not change with altitude, and only the wave's intrinsic phase speed, equivalent depth, and 


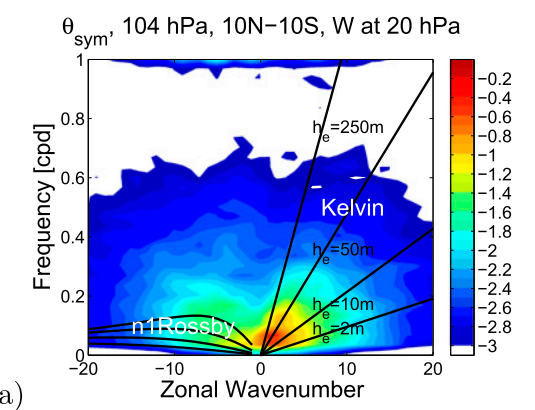

a)

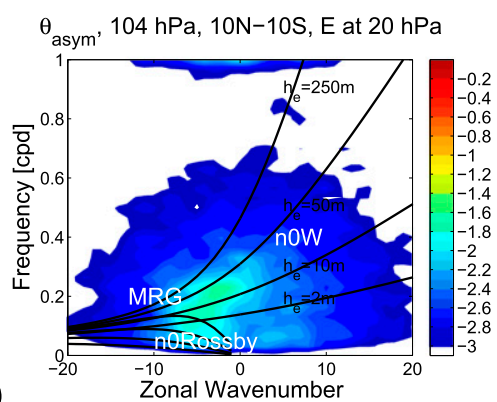

$\theta_{\text {sym }}, 30 \mathrm{hPa}, 10 \mathrm{~N}-10 \mathrm{~S}, \mathrm{~W}$ at $20 \mathrm{hPa}$

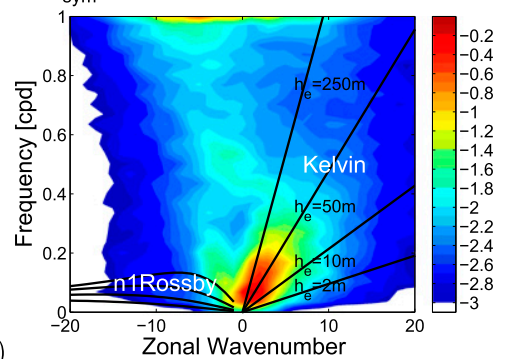

b)

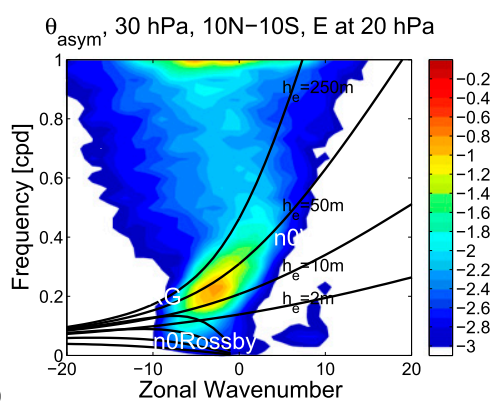

c)
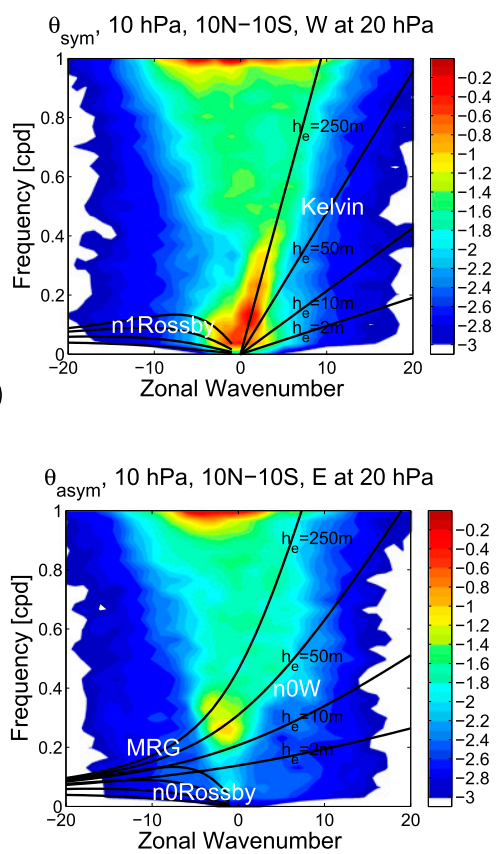

FIG. 4. (a)-(c) Symmetric wavenumber-frequency spectra of the temperature variance $\left[\log \left(\mathrm{K}^{2}\right)\right]$ at 104,30 , and $10 \mathrm{hPa}$ during the QBO westerly phase. The dispersion lines of Kelvin waves and $\mathrm{n} 1$ equatorial Rossby waves with equivalent depths of 2, 10, 50, and 250 m are superimposed on the plots. (d)-(f) As in (a)-(c), but for the antisymmetric waves during the QBO easterly phase and with the dispersion lines of n0 equatorial Rossby waves, mixed Rossby-gravity waves, and n0 westerly waves. Negative wavenumbers indicate easterly waves.

vertical wavenumber are Doppler shifted. Hence, assuming linearity, the signal of a wave will remain at the same place in the ground-based wavenumber-frequency spectra at every altitude.

Figures $4 \mathrm{a}-\mathrm{c}$ show the symmetric wavenumberfrequency spectra at 104,30 , and $10 \mathrm{hPa}$ averaged over the 14 months defined as QBO westerly phase during the first 30 years of the piControl run as described in section 3. Figures $4 d-f$ show the antisymmetric spectrum at the same pressure levels averaged over the 14 months defined as the QBO easterly phase. Before applying the Fourier transform, the temperature perturbations have been decomposed into symmetric and antisymmetric parts as described in section 4 . Then, 14 individual spectra have been computed over the 14 individual months separately for each latitude using a time window of 30 days, and then averaged over the 14 spectra and from $10^{\circ} \mathrm{N}$ to $10^{\circ} \mathrm{S}$. The input frequency of the data is four samples per day. Figure 4 also shows the dispersion lines of Matsuno-type equatorial waves (Matsuno 1966) with equivalent depths of $2,10,50$, and $250 \mathrm{~m}$ assuming zero background wind.

A direct downward influence of the wind field on the wave field is impossible in the tropical stratosphere (Plumb 1977). Accordingly, despite the potential influence of the QBO on tropical convection (Giorgetta et al. 1999; Liess and Geller 2012), the wavenumber-frequency spectra at $104 \mathrm{hPa}$, just above the convective wave sources and below the region influenced by the QBO, are qualitatively equal during the QBO westerly and easterly phase (not shown). Waves framed by the dispersion lines of Kelvin and equatorial Rossby waves dominate the symmetric spectrum (Fig. 4a). In the antisymmetric wave spectrum, mixed Rossby-gravity waves (MRG waves) show the largest variance at easterly zonal wavenumbers, while there is relatively little power at westerly wavenumbers (Fig. 4d).

During the months defined as QBO westerly phase, the zonal wind below $20 \mathrm{hPa}$ is easterly (see solid vertical lines in Fig. 1b) and, thus, favorable for the propagation of westerly waves (Ern et al. 2008; Yang et al. 2011). However, comparing the wave spectra at 104 and $30 \mathrm{hPa}$ in Figs. $4 \mathrm{a}$ and $4 \mathrm{~b}$ shows that Kelvin waves with groundbased phase speeds slower than $10 \mathrm{~m} \mathrm{~s}^{-1}\left(h_{e}<10 \mathrm{~m}\right)$ are absorbed within the easterly flow in the lower stratosphere and, thus, cannot contribute to the QBO westerly jet's forcing. As shown by Ern et al. (2009a) and later in this paper, Kelvin waves are mostly radiatively damped, and the damping becomes more efficient with decreasing Doppler shifted phase speed. Apparently, the slow Kelvin waves are slow enough for efficient radiative wave damping even within easterly flow. Because of the decrease of density with altitude, the power of the remaining waves increases, especially at frequencies 
higher than $0.4 \mathrm{cpd}$. The QBO westerly jet, which starts at $20 \mathrm{hPa}$, strongly filters westerly waves. Thus, at $10 \mathrm{hPa}$, the symmetric spectrum lacks Kelvin waves with phase speeds slower than $20 \mathrm{~ms}^{-1}\left(h_{e}<50 \mathrm{~m}\right)$ and mostly shows Kelvin waves with phase speeds faster than $50 \mathrm{~m} \mathrm{~s}^{-1}\left(h_{e}>250 \mathrm{~m}\right.$; Fig. 4c). This illustrates that the westerly jet is forced by waves with phase speeds considerably faster than the jet itself.

During the QBO easterly phase, antisymmetric waves with frequencies larger than $0.1 \mathrm{cpd}$ propagate to $30 \mathrm{hPa}$ undisturbed (cf. Figs. $4 \mathrm{~d}$ and $4 \mathrm{e}$ ). At $30 \mathrm{hPa}$, just below the onset of the QBO easterly jet, MRG waves dominate the antisymmetric spectrum (Fig. 4e). Between 30 and $10 \mathrm{hPa}$, the QBO easterly jet strongly filters easterly waves slower than $30 \mathrm{~m} \mathrm{~s}^{-1}$ (cf. Figs. $4 \mathrm{e}$ and $4 \mathrm{f}$ ). However, a distinct peak of the spectral power displays the presence of very fast MRG waves with zonal wavenumbers lower than 5 and frequencies higher than $0.3 \mathrm{cpd}$. These waves are fast enough to propagate through the easterly jet into the middle and upper stratosphere. This is consistent with observations, which show that high-speed Rossby gravity waves can even reach the mesopause region (Garcia and Lieberman 2005; Ern et al. 2009b).

The discussion above omitted the antisymmetric and symmetric wave spectra, respectively, during the QBO westerly and easterly phase, respectively. The symmetric wave spectrum is dominated by westerly Kelvin waves, which are mostly filtered within the westerly flow below $20 \mathrm{hPa}$ during the QBO easterly phase. Hence, during the QBO easterly phase, the symmetric wave spectrum at $30 \mathrm{hPa}$ qualitatively resembles the symmetric wave spectrum at $10 \mathrm{hPa}$ during the QBO westerly phase (not shown). Similarly, the MRG waves, which dominate the antisymmetric wave spectrum, are strongly filtered below $30 \mathrm{hPa}$ during the QBO westerly phase, when the zonal wind below $20 \mathrm{hPa}$ is easterly (not shown).

\section{b. Vertical structure of Kelvin waves}

Consistent with results presented by Ern and Preusse (2009b) and Yang et al. (2011), the loss of spectral power with altitude shown above illustrates the filtering of atmospheric waves by the QBO jets. In this section, the dynamical and physical processes leading to the observed wave attenuation are investigated. These wave dissipation processes depend on the wave-induced gradients of temperature and wind and, hence, the evolution of the waves' vertical wavelength (Fels 1982). In the following, the connection between wave structure and wave damping is discussed based on Fig. 5, which shows the time-height cross section of temperature perturbations induced by two sets of Kelvin waves. The focus lies on Kelvin waves as they are generally well developed in MPI-ESM (Fig. 4) and other models (Lott et al. 2014) and contribute most to the forcing of the QBO westerly jet (shown below). The waves have been isolated by first applying a fast Fourier transformation in longitude and time on the symmetric temperature field at every model level and at every latitude. The latitudinal and temporal means have been subtracted from the data prior to the spectral decomposition, but no detrending and no tapering has been applied. Then, only the spectral components at wavenumbers ranging from 1 to 5 , frequencies ranging from 0 to $0.5 \mathrm{cpd}$, and ground-based phase speeds between 10 and $20 \mathrm{~m} \mathrm{~s}^{-1}$ (Figs. 5a,d) and between 20 and $50 \mathrm{~m} \mathrm{~s}^{-1}$ (Figs. $5 \mathrm{~b}, \mathrm{e}$ ), respectively, have been transformed back to physical space by applying the inverse fast Fourier transform on the spectra at each pressure level and each latitude. The chosen range of a phase's speeds corresponds to the dispersion lines of Kelvin waves with equivalent depths of 10,50 , and $250 \mathrm{~m}$, which dominate the stratospheric wave spectrum (Figs. $4 a-c$ ).

The cross sections in Figs. 5a and 5b and Figs. 5d and 5e show two of the months defined as QBO westerly and easterly phase, respectively. The zero wind line between the upper- and the lower-level QBO jets is indicated by a black horizontal line at $20 \mathrm{hPa}$. Though the reconstructed wave fields have particular characteristics depending on the month, latitude, and longitude for which they are representative, the qualitative results discussed next are robust with respect to these parameters. Figures $5 \mathrm{c}$ and $5 \mathrm{f}$ show the zonal wind profiles and the theoretical vertical wavelengths $(2 \pi / m)$ of Kelvin waves with ground bases phase speeds of 10,20, and $50 \mathrm{~m} \mathrm{~s}^{-1}$ for zero background wind (dashed black lines) and including Doppler shift (solid gray lines) during the two months. The vertical wavenumber $m$ of Kelvin waves relates to the intrinsic phase speed $c-\bar{u}$ and $h_{e}$ as

$$
m=\frac{N}{c-\bar{u}}=\frac{N}{\sqrt{g h_{e}}}
$$

where $N$ is the buoyancy frequency.

The slow and fast sets of Kelvin waves (low and high equivalent depths) have vertical wavelengths of roughly 5 and $10 \mathrm{~km}$, respectively, within the lower-level QBO easterly jet (Figs. 5a,b) and of 2 and $7.5 \mathrm{~km}$, respectively, within the lower-level QBO westerly jet (Figs. 5d,e). These values are in accordance with the Doppler-shifted theoretical values (Figs. 5c,f).

During the QBO easterly phase, the slow Kelvin waves meet critical levels within the lower-level QBO westerly jet, where their intrinsic phase speed and hence, their vertical wavelengths become zero (Fig. 5f). The waves do not propagate beyond that level (Fig. 5d) and, as shown 
$\mathrm{T}, \mathrm{T}_{\mathrm{t} \mid \mathrm{LW}}, \mathrm{Kel}, 10<\mathrm{c}<20 \mathrm{~m} / \mathrm{s}, 2 \mathrm{~N} 210 \mathrm{E}$

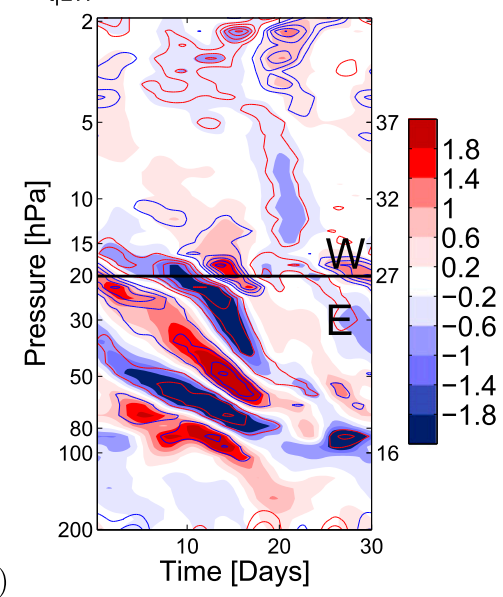

a)

$\mathrm{T}, \mathrm{T}_{\mathrm{t} \mid \mathrm{LW}}, \mathrm{Kel}, 10<\mathrm{c}<20 \mathrm{~m} / \mathrm{s}, 2 \mathrm{~N} 210 \mathrm{E}$

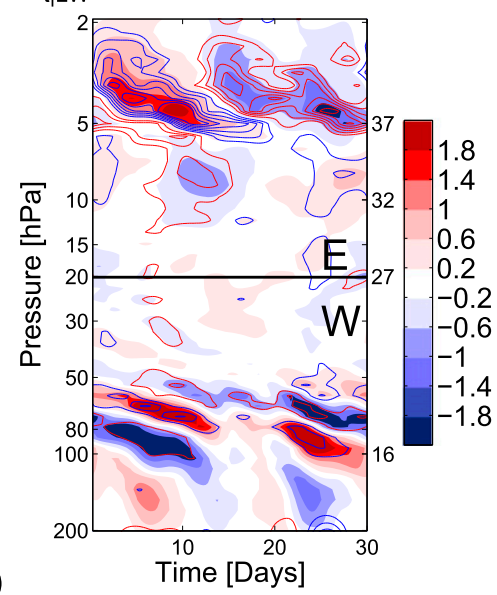

$T, T_{t \mid L W}, K e l, 20<c<50 \mathrm{~m} / \mathrm{s}, 2 \mathrm{~N} 210 \mathrm{E}$

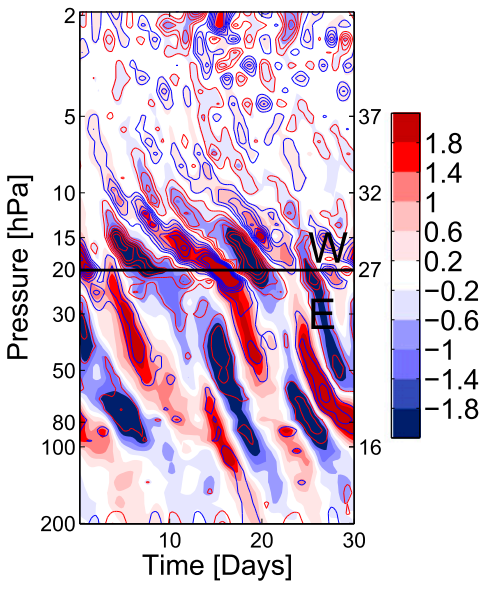

b)
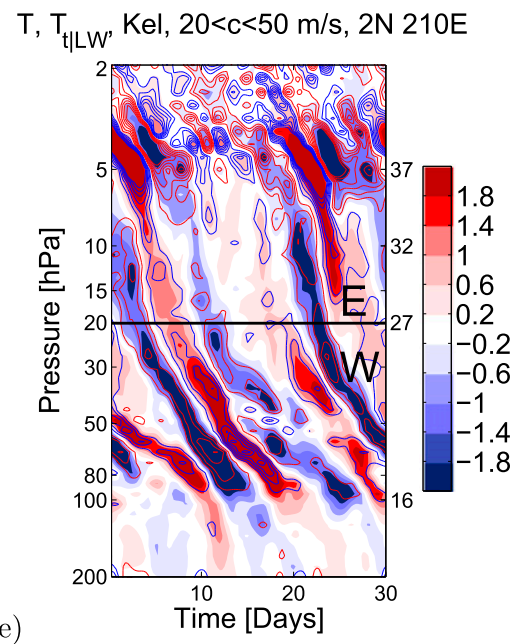

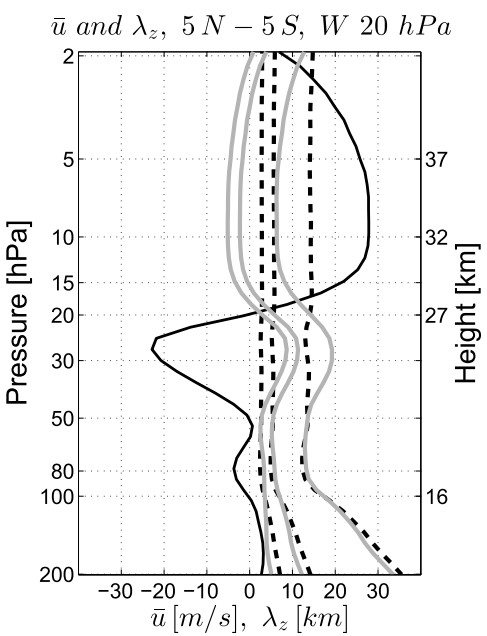

c)

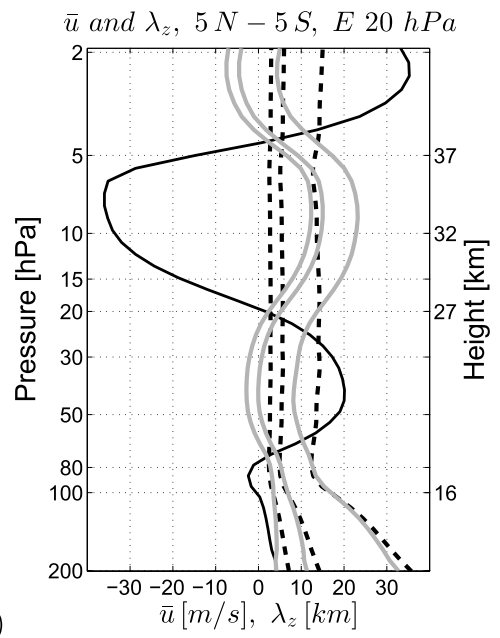

FIG. 5. Temperature perturbation (K) induced by Kelvin waves (shading) with ground-based phase speeds (a),(d) between 10 and $20 \mathrm{~m} \mathrm{~s}^{-1}$ and (b),(e) between 20 and $50 \mathrm{~m} \mathrm{~s}^{-1}$ during one month classified as the QBO (a),(b) westerly and (d),(e) easterly phases. The contour lines indicate the longwave radiative temperature tendencies associated with the Kelvin waves. The contour interval is $0.01 \mathrm{~K} \mathrm{day}^{-1}$. Positive and negative tendencies are drawn in red and blue, respectively. (c),(f) The zonal mean zonal wind ( $\mathrm{m} \mathrm{s}^{-1}$, solid black) and theoretical vertical wavelengths of Kelvin waves $(\mathrm{km})$ with ground-based phase speeds of 10,20 , and $50 \mathrm{~m} \mathrm{~s}^{-1}$ with and without Doppler shift (dashed black and gray, respectively) during the two months are shown in (a),(b) and (d),(e), respectively.

below, deposit westerly momentum. The same Doppler shift of the vertical wavelengths and the resulting dissipation of the slow Kelvin waves can be observed within the QBO westerly jet above $20 \mathrm{hPa}$ in Figs. 5a and 5c.

Because of the strong easterly winds between 50 and $30 \mathrm{hPa}$ during the QBO westerly phase, Eq. (1) predicts a Doppler shift of all selected waves to large vertical wavelengths (Fig. 5c). However, the layer is too shallow for the waves to adjust, and their vertical wavelength does not change as strongly as predicted (Figs. 5a,b). The QBO westerly and easterly jets above $20 \mathrm{hPa}$ in Figs. 5a and 5b and Figs. 5d and 5e, respectively, extend over a large vertical layer and the waves adjust their vertical wavelengths according to Eq. (1).
When the fast Kelvin waves enter the strong QBO westerly jet above $20 \mathrm{hPa}$, their wavelengths halve from 10 to $5 \mathrm{~km}$ and the waves do not propagate beyond $10 \mathrm{hPa}$ (Figs. 5b,c). However, during the QBO easterly phase, the fast Kelvin waves propagate through the weaker QBO westerly jet in the lower stratosphere, and their vertical wavelength increases from 10 to $20 \mathrm{~km}$ within the QBO easterly jet above $20 \mathrm{hPa}$ (Figs. 5e,f). In the month selected to represent the QBO easterly phase, a westerly jet of the semiannual oscillation is located above $5 \mathrm{hPa}$ (Fig. 5f). Here, the vertical wavelength of the fast Kelvin waves again decreases from 20 to $5 \mathrm{~km}$, which is followed by the waves' dissipation (Figs. 5e,f). 


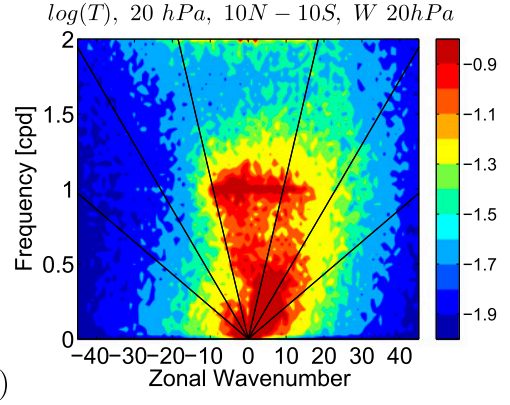

a)

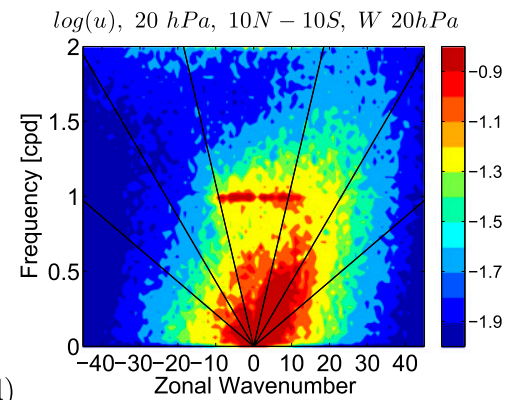

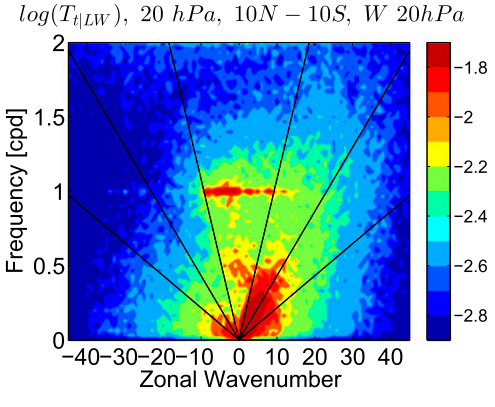

$\log \left(u_{t \mid h d i f f}\right), 20 h P a, 10 N-10 S, W 20 h P a$

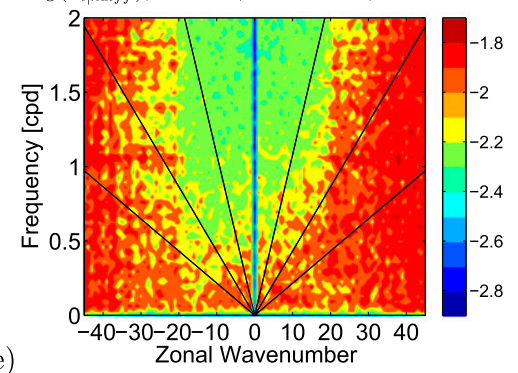

$T / T_{t \mid L W}, 20 h P a, 10 N-10 S, W 20 h P a$

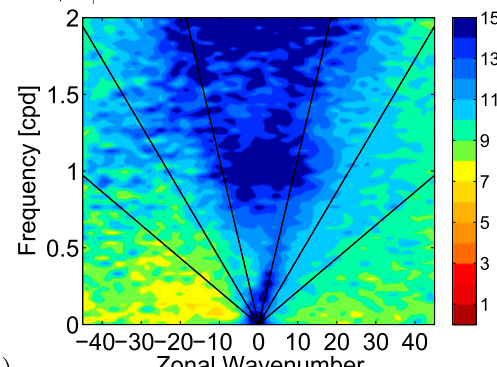

c)

$u / u_{t \mid h d i f f}, 20 h P a, 10 N-10 S, W 20 h P a$

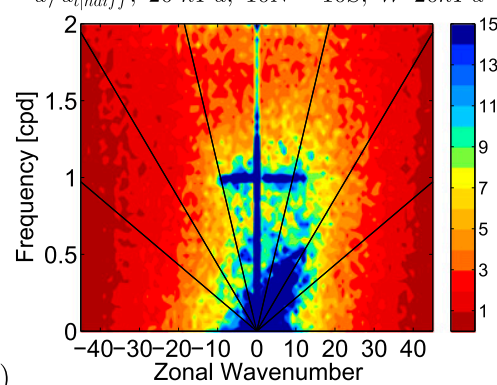

FIG. 6. Latitudinal mean $\left(10^{\circ} \mathrm{N}-10^{\circ} \mathrm{S}\right)$ symmetric wavenumber-frequency spectra of the amplitudes of (a) temperature [log(K)], (b) the longwave radiative temperature tendency $\left[\log \left(\mathrm{K} \mathrm{day}^{-1}\right)\right]$, (c) the $e$-folding time of the temperature perturbations due to longwave radiative damping (days), (d) the zonal wind $\left[\log \left(\mathrm{m} \mathrm{s}^{-1}\right)\right]$, (e) the horizontal diffusion of the zonal wind $\left[\log \left(\mathrm{m} \mathrm{s}^{-1} \mathrm{day}^{-1}\right)\right]$, and (f) the $e$-folding time of the zonal wind perturbation due to horizontal diffusion (days). All panels show the amplitudes at $20 \mathrm{hPa}$ averaged over months defined as the QBO westerly phase. Note the different scales of the shading. Black lines indicate constant phase speeds of $\pm 10,50$, and $100 \mathrm{~m} \mathrm{~s}^{-1}$. Negative wavenumbers indicate easterly waves.

\section{c. Wave damping}

The shortening of the Kelvin waves' vertical wavelengths within westerly flow and the resulting increase of the waves' amplitudes facilitates longwave radiative heat loss (Fels 1982; Zhu 1993; Hitchcock et al. 2010), which is illustrated by the contour lines depicting the longwave radiative temperature tendencies associated with the isolated Kelvin waves in Fig. 5. The tendencies have been isolated the same way as the wave-induced temperature perturbations as described in section $5 \mathrm{~b}$. The temperature and the temperature tendencies have the same vertical structure and are almost perfectly in phase (Fig. 5). Their average correlation coefficient between 100 and $10 \mathrm{hPa}$ is -0.97 . Within the QBO westerly jet, the waves' phase speed is Doppler shifted to lower values, which coincides with large radiative tendencies (Figs. 5a,b,d). Hence, an individual air parcel experiences the temperature perturbation and the anticorrelated tendency for an increased amount of time, which enhances the radiative wave damping. Within the QBO westerly jet above $20 \mathrm{hPa}$ in Figs. 5a and 5b, the time an air parcel's temperature is perturbed matches the radiative time scales and the shown Kelvin waves dissipate quickly. When the QBO westerly jet is in the lower stratosphere and relatively weak as in Figs. 5d and 5e, the Doppler-shifted phase speed of the slow Kelvin waves is low enough for them to dissipate below $30 \mathrm{hPa}$ (Fig. 5d), whereas the still relatively large intrinsic phase speed of the fast Kelvin waves allows them to propagate beyond the westerly jet into the upper stratosphere (Fig. 5e).

Ern et al. (2009a) showed that Kelvin waves that are faster than the QBO westerly jet are mostly damped by longwave radiation. To estimate the contribution of radiative and diffusive processes to the wave damping in the GCM applied here, Fig. 6 shows the amplitude spectrum (absolute value of the spectral coefficients) of temperature, the longwave radiative temperature tendencies, the zonal wind, and the horizontal zonal wind diffusion at $20 \mathrm{hPa}$ during the QBO westerly phase. The temperature spectrum shows Kelvin waves faster than $10 \mathrm{~m} \mathrm{~s}^{-1}$, a mix of gravity waves with frequencies higher than $0.5 \mathrm{cpd}$ and wavenumbers lower than 20 , and atmospheric tides (Fig. 6a). At wavenumbers larger than 20 , the temperature amplitudes vary little with frequency and decrease continuously with increasing wavenumber. The spectrum of the zonal wind amplitudes is qualitatively equal to the temperature spectrum (cf. Figs. 6a and 6d). Also, the amplitudes of the longwave radiative tendency 
organize similar to the temperature spectrum (cf. Figs. $6 \mathrm{a}$ and $6 \mathrm{~b}$ ), which is to be expected as longwave radiation follows Planck's law and is a function of temperature.

In MPI-ESM, horizontal diffusion does not involve a physical model of subgrid-scale processes but, as in many models, is expressed in the form of an eighth-order Laplacian, which is a numerically convenient form of scale-selective diffusion with empirically determined coefficients to ensure a realistic behavior of the resolved scales (Roeckner et al. 2003). The horizontal diffusion is zero at wavenumber 0 and increases with increasing zonal wind and wavenumber. At wavenumbers lower than \pm 20 and frequencies lower than $0.5 \mathrm{cpd}$, the amplitudes of horizontal diffusion are strong (Fig. 6e) as, at such scales, the amplitudes of the zonal wind perturbations are also strong (Fig. 6d). However, the spectrum of the horizontal diffusion does not organize in, for example, Kelvin waves (Fig. 6d). The dominant factor of the horizontal diffusion is the zonal wavenumber: for wavenumbers beyond \pm 20 the horizontal diffusion increases sharply over all frequencies (Fig. 6d).

Figures $6 \mathrm{c}$ and $6 \mathrm{f}$ show the amplitude spectra of temperature and the zonal wind divided by the amplitude spectra of the longwave radiative temperature tendency and the diffusive zonal wind tendency, respectively. These $e$-folding time scales are first-order approximations of the time that longwave radiation and horizontal diffusion need to damp the wave-induced temperature and zonal wind perturbations. The efficiency of a damping process increases with decreasing time scale.

Theoretical studies showed that the radiative damping is more efficient for waves with low vertical wavelengths [see Fels (1982) and discussion therein]. Accordingly, the radiative time scales in MPI-ESM vary little with zonal wavenumber and increase with increasing phase speed (Fig. 6c) and, hence, with increasing vertical wavelength. The diffusive time scales, however, shorten with increasing wavenumber and vary little with frequency (Fig. 6f). For Kelvin waves with wavenumbers between 0 and 10 and frequencies lower than $0.5 \mathrm{cpd}$, the radiative time scales are shorter than the diffusive time scales (cf. Fig. 6c and 6f). Hence, longwave radiation is the dominant damping mechanism for these waves. However, with increasing wavenumber, the temperature and zonal wind perturbations decrease (Figs. 6a,d), whereas the horizontal wind diffusion increases (Fig. $6 \mathrm{e})$. Thus, the diffusive time scales become shorter than the radiative time scales and, hence, dominate the wave damping. So the choice of the numerical diffusion scheme, which is needed for the closure of the discretized dynamics, matters for the high-wavenumber spectrum in general, and for wave-mean flow interaction driving the QBO in particular.

Note that, in the model, the numerical horizontal temperature diffusion and the numerical meridional and vertical diffusion of the dynamic variables are an order of magnitude weaker than the values just presented and, hence, are not important for the wave damping in MPI-ESM.

\section{Resolved wave forcing}

The influence of the mean flow on the propagation of tropical waves has been shown above. Next, the actual forcing of the QBO easterly and westerly jets that results from the wave attenuation will be discussed based on the 209 quasi-biennial cycles of the first 500 years of the piControl run. Such an analysis has been presented for high resolution models by Kawatani et al. (2010a) and Evan et al. (2012), but it is still missing for GCMs with a relatively course resolution comparable to MPI-ESM, which, however, still form the majority of operational GCMs.

The stratospheric wave forcing is commonly described within the framework of the transformed Eulerian-mean (TEM) equations (Andrews et al. 1987). Within this framework, the Eliassen-Palm flux $\mathbf{F}$ and its divergence $\boldsymbol{\nabla} \cdot \mathbf{F}$ are measures of the transport and deposition of zonal momentum and heat by atmospheric waves (Andrews et al. 1987). To distinguish the contribution of waves with different zonal wavenumbers, frequencies, and phase speeds to the zonal wind tendency, the spectral distribution of the EP flux is computed following Horinouchi et al. (2003):

$$
\begin{aligned}
\frac{F^{(\phi)}(k, \omega)}{\rho_{0} a \cos \phi}= & \operatorname{Re}\left[\bar{u}_{z} \hat{v}(k, \omega) \hat{\theta}^{*}(k, \omega) / \bar{\theta}_{z}\right] \\
& -\operatorname{Re}\left[\hat{u}(k, \omega) \hat{v}^{*}(k, \omega)\right] \\
\frac{F^{(z)}(k, \omega)}{\rho_{0} a \cos \phi}= & \operatorname{Re}\left\{\left[f-\frac{(\bar{u} \cos \phi)_{\phi}}{a \cos \phi}\right] \hat{v}(k, \omega) \hat{\theta}^{*}(k, \omega) / \bar{\theta}_{z}\right\} \\
& -\operatorname{Re}\left[\hat{u}(k, \omega) \hat{w}^{*}(k, \omega)\right] .
\end{aligned}
$$

In Eqs. (2) and (3), $\rho_{0}$ is the log-pressure heightdependent density, $a$ is Earth's radius, $\phi$ and $z$ are the latitude and the log-pressure height, respectively, and $f$ is the Coriolis parameter $(f \equiv 2 \Omega \sin \phi$, where $\Omega$ is the rotation rate of Earth); $u, v, w$, and $\theta$ are the zonal, meridional, and vertical wind and the potential temperature, 

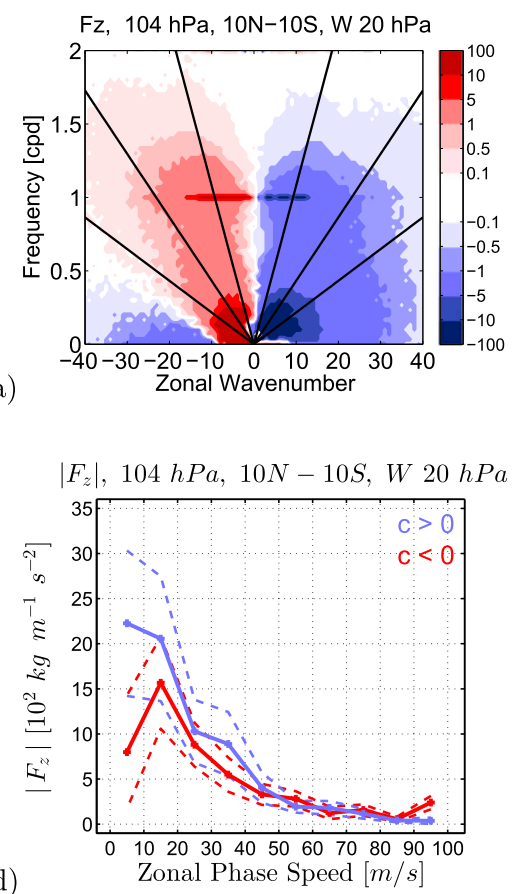

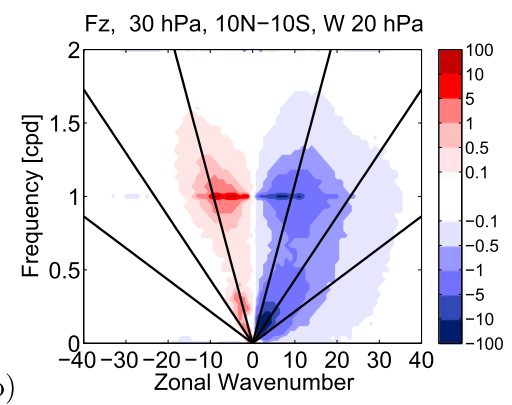

$\left|F_{z}\right|, 30 h P a, 10 N-10 S, W 20 h P a$

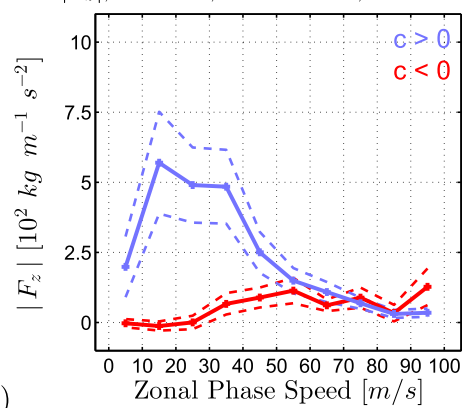

c)

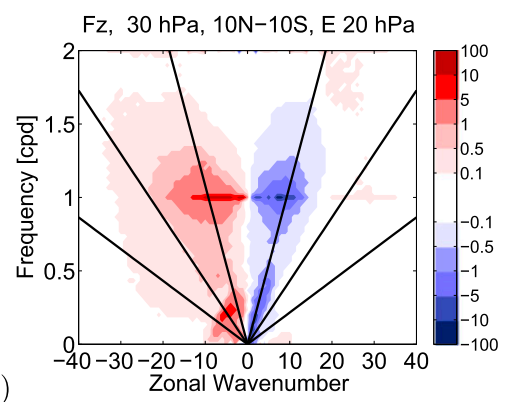

$\left|F_{z}\right|, 30 h P a, 10 N-10 S, E 20 h P a$

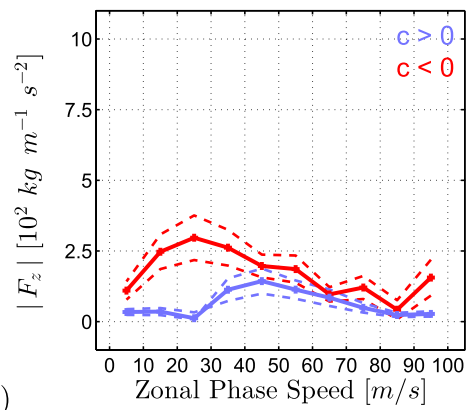

FIG. 7. Latitudinal-mean $\left(10^{\circ} \mathrm{N}-10^{\circ} \mathrm{S}\right)$ zonal wavenumber-frequency spectra of the vertical EP flux $\left(\mathrm{kg} \mathrm{m}^{-1} \mathrm{~s}^{-2}\right)$ (a) at 104 and (b) at $30 \mathrm{hPa}$ during the QBO westerly phase and (c) at $30 \mathrm{hPa}$ during the QBO easterly phase. The black lines indicate constant phase speeds of $\pm 10,50$, and $100 \mathrm{~m} \mathrm{~s}^{-1}$. Negative wavenumbers indicate easterly waves. (d)-(f) The EP flux shown in (a)-(c) for easterly (red) and westerly (blue) waves integrated over discrete pairs of wavenumbers and frequencies that correspond to $10 \mathrm{~m} \mathrm{~s}^{-1}$ bins of constant phase speeds. Thin dashed lines indicate the standard deviations within the 209 EP flux spectra for each phase speed bin.

respectively. An overbar denotes the zonal mean of the variables, a hat denotes the Fourier coefficients, and an asterisk denotes the complex conjugate. The Fourier coefficients have been derived by applying a fast Fourier transform in longitude and time at each latitude for each of the 209 months defined as QBO westerly and easterly phase, respectively; $u, v, w$, and $\theta$ have not been decomposed into symmetric and antisymmetric components, have not been detrended, and have not been tapered before calculating the spectral EP flux. The EP flux and the EP-flux divergence for each individual month have been averaged over the individual spectra and from $10^{\circ} \mathrm{N}$ to $10^{\circ} \mathrm{S}$. In Eqs. (2) and (3), subscripts $\phi$, $z$, and $t$ denote the meridional, vertical, and temporal derivatives; $k$ and $\omega$ denote the zonal wavenumber and frequency. In this study, $\mathbf{F}$ denotes the EP flux carried by waves resolved in MPI-ESM-MR with $k$ ranging from 0 to 63 .

\section{a. Spectral distribution of vertical EP flux}

The wavenumber-frequency spectrum of the vertical EP flux at $104 \mathrm{hPa}$, below the region influenced by the QBO, is shown in Fig. 7a. Except for the diurnal peak, the spectrum is red in wavenumber and frequency and continuous over the whole spectral range. The EP flux is largest at wavenumbers lower than 20 and frequencies lower than $0.5 \mathrm{cpd}$, where the spectrum shows an asymmetry such that the decrease of the momentum flux with wavenumber is less pronounced at positive (westerly) than negative (easterly) wavenumbers. This is associated with a reversal of the sign of the EP flux at wavenumbers lower than -10 , probably owing to the Doppler shift of very slow Kelvin waves (Ortland and Alexander 2011). The EP flux stays almost constant at frequencies ranging from 0.5 to $1 \mathrm{cpd}$. Peaks at $1 \mathrm{cpd}$ are due to atmospheric tides. At frequencies higher than $1 \mathrm{cpd}$, the momentum flux decreases quickly. In Fig. 2b, it has been shown that compared to TRMM, MPI-ESM underestimates the variability of precipitation with wavenumbers higher than 20 and periods shorter than 5 days. Though, in general, convectively triggered waves are strongly filtered in the uppermost troposphere and, thus, the stratospheric wave spectrum is not expected to completely match the spectrum in the troposphere (Lott et al. 2014), the shortage of precipitation variability at high wavenumbers and frequencies in MPI-ESM indicates that MPI-ESM will underestimate the EP flux at these frequencies and wavenumbers also in the stratosphere.

Figure 4 showed that equatorial waves are filtered depending on their zonal phase speed rather than their 
wavenumber or frequency. Hence, the distribution of the wave momentum among zonal phase speeds contains information about the potential forcing of the QBO jets. Figure 7d shows the EP flux at $104 \mathrm{hPa}$ integrated over discrete pairs of wavenumbers and frequencies that correspond to $10 \mathrm{~m} \mathrm{~s}^{-1}$ bins of constant phase speeds. The EP flux carried by westerly waves (blue line in Fig. 7d) is largest at phase speeds between 0 and $10 \mathrm{~m} \mathrm{~s}^{-1}$. For easterly waves (red line in Fig. 7d) the maximum is shifted to higher phase speeds between -10 and $-20 \mathrm{~m} \mathrm{~s}^{-1}$. The wave momentum flux decreases continuously with increasing phase speed, and waves faster than $\pm 40 \mathrm{~m} \mathrm{~s}^{-1}$ carry less than $10 \%$ of the total EP flux. Easterly waves carry less momentum than westerly waves, especially at low phase speeds. As in MPI-ESM, the variance of tropical precipitation and, hence, the convective wave source is balanced between easterly and westerly waves (Fig. 2b); the imbalance of the wave momentum flux at $104 \mathrm{hPa}$ indicates stronger filtering of easterly waves in the uppermost troposphere.

The dashed lines in Fig. 7d indicate the standard deviations within the 209 binned EP flux spectra for each phase speed bin. The standard deviations reach $30 \%$ of the mean values. This variability is partly seasonal and contributes to the stalling of the QBO easterly jet in the lower stratosphere and, together with parameterized waves and advection, modulates the downward propagation rate of the QBO jets (Krismer et al. 2013).

Figures $7 \mathrm{~b}$ and $7 \mathrm{e}$ and Figs. $7 \mathrm{c}$ and $7 \mathrm{f}$ show the wavenumber-frequency spectra and the phase speed distribution of the vertical EP flux at $30 \mathrm{hPa}$ during the QBO westerly and easterly phase, respectively. The EP flux carried by waves propagating into the direction of the mean flow below $20 \mathrm{hPa}$ (easterly waves in Figs. 7b and $7 \mathrm{e}$ and westerly waves in Figs. 7c and 7f) is strongly reduced. However, the flux carried by waves with phase speeds opposite to the mean flow also decreases (westerly waves in Figs. 7b and 7e and easterly waves in Figs. 7c and $7 \mathrm{f}$ ), most strongly at low phase speeds. Once more, this illustrates the weakening of waves due to radiation and diffusion, even in the absence of critical levels.

\section{b. Change of EP flux with altitude}

The connection between the background wind field and the phase speed distribution of the wave momentum flux and the wave forcing is displayed in Figs. $8 \mathrm{a}$ and $8 \mathrm{~b}$, which show profiles of the vertical EP flux as a function of the ground-based zonal phase speed averaged over the months defined as QBO westerly and easterly phase. To emphasize the change of the wave momentum flux with altitude rather than with phase speed, the flux in every phase speed bin has been normalized by its value at $104 \mathrm{hPa}$. Figures $8 \mathrm{c}$ and $8 \mathrm{~d}$ show the profiles of the zonal wind tendency due to the total EP flux divergence $\left(\nabla \cdot\left[F_{y}, F_{z}\right]\right)$, also as a function of the zonal phase speed. The zonal wind profiles during the two QBO phases are superimposed on the plots.

During both phases, the vertical EP flux carried by waves slower than $20 \mathrm{~m} \mathrm{~s}^{-1}$ strongly decreases in the lowermost stratosphere between 100 and $80 \mathrm{hPa}$ (Figs. $8 \mathrm{a}, \mathrm{b})$, where the zonal wind is weak and there are no well-defined QBO jets. This leads to pronounced easterly and westerly momentum deposition (Figs. 8c and $8 d$ ) and little net acceleration of the mean flow. During the QBO westerly phase, the winds are weak up to $50 \mathrm{hPa}$ (Figs. 8a,c) and longwave radiative damping of the slow westerly waves strongly reduces the wave momentum available to force the QBO westerly jet at higher altitudes. A comparison of the vertical EP flux at $104 \mathrm{hPa}$ and below the QBO westerly jet at $30 \mathrm{hPa}$ in Figs. $7 \mathrm{~d}$ and $7 \mathrm{e}$ demonstrates that westerly waves with phase speeds between 10 and $20 \mathrm{~m} \mathrm{~s}^{-1}$ and between 20 and $50 \mathrm{~m} \mathrm{~s}^{-1}$ deposit about $75 \%$ and $50 \%$, respectively, of the vertical EP flux within the lower-level QBO easterly jet, which strongly reduces the wave momentum available to force the QBO westerly jet at higher altitudes.

In regions where the QBO jets are well developedlike the westerly jet above $20 \mathrm{hPa}$ in Fig. $8 \mathrm{a}$ and between 70 and $20 \mathrm{hPa}$ in Fig. $8 \mathrm{~b}$ and the easterly jet above $20 \mathrm{hPa}$ in Fig. 8b-waves with phase speeds opposite to the direction of the mean flow propagate upward without much loss of vertical EP flux. Waves propagating in the direction of the zonal wind-like westerly waves above $20 \mathrm{hPa}$ in Fig. $8 \mathrm{a}$ or below $20 \mathrm{hPa}$ in Fig. $8 \mathrm{~b}$ and easterly waves above $20 \mathrm{hPa}$ in Fig. $8 \mathrm{~b}$-lose momentum to the flow. The tilt of the contour lines toward higher phase speeds indicates that with the strengthening of the QBO jets at higher altitudes, ever-faster waves deposit wave momentum as their intrinsic phase speeds decrease and radiative wave damping becomes more efficient. Where waves meet critical levels where $c-\bar{u}=0$, the wavemomentum flux reduces to less than $1 \%$ of its reference value at $100 \mathrm{hPa}$.

When located in the lower stratosphere, the QBO westerly jet is mostly forced by waves with phase speeds between 0 and $10 \mathrm{~m} \mathrm{~s}^{-1}$ (Fig. 8d). As just described, these waves do not propagate high enough to reach the QBO westerly jet if located at $20 \mathrm{hPa}$, where the forcing of the westerly jet is mostly due to waves with phase speeds between 10 and $40 \mathrm{~m} \mathrm{~s}^{-1}$ (Fig. 8c). This means that waves almost twice as fast as the QBO jet still contribute to its forcing. Because of longwave radiative damping, the forcing of the QBO westerly jet can focus within a narrow layer between 30 and $15 \mathrm{hPa}$ (Fig. 8c), even though most of the waves are still faster than the westerly jet and do not meet critical levels. Above $5 \mathrm{hPa}$, 

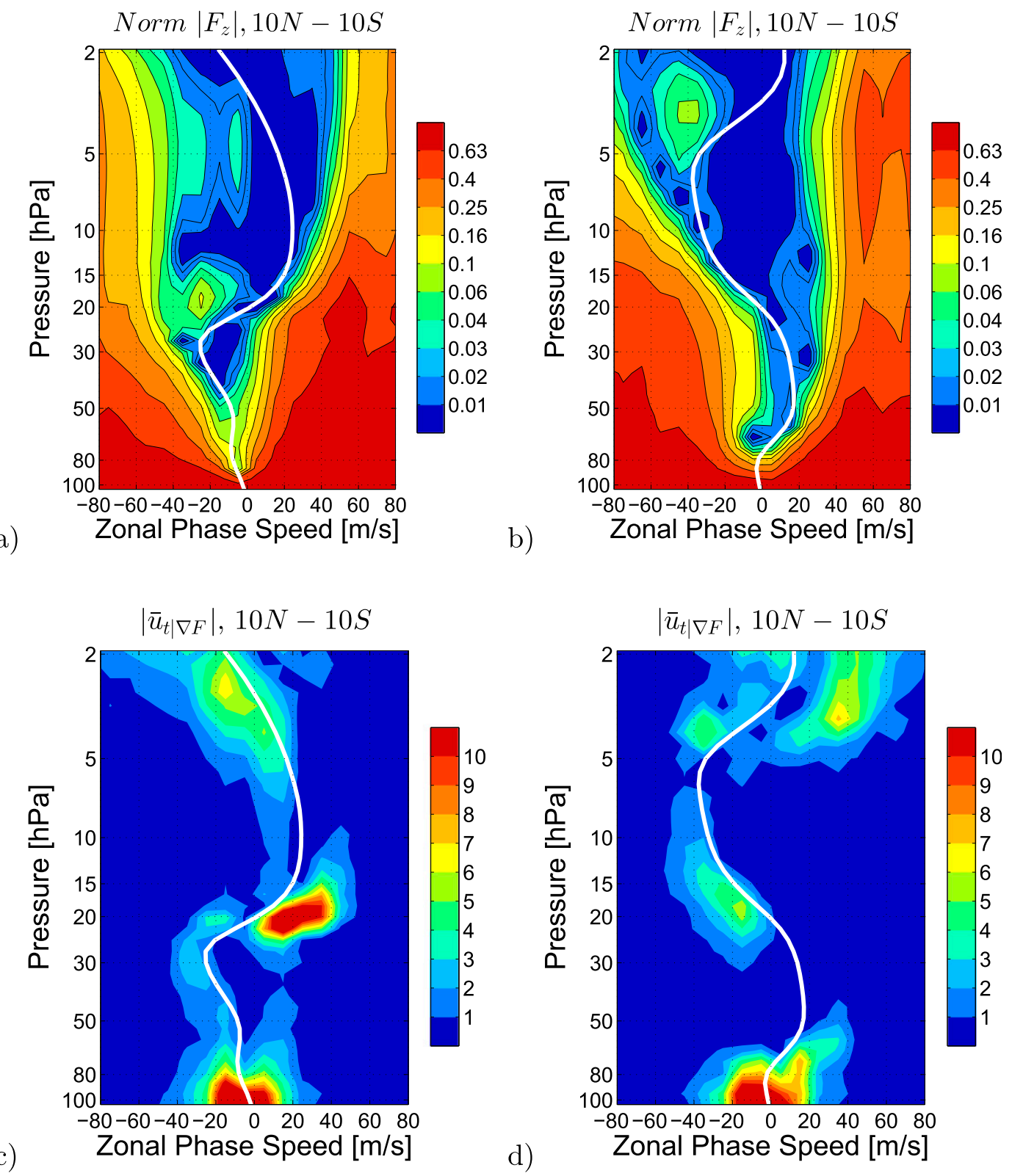

FIG. 8. Profiles of (a),(b) latitudinal-mean $\left(10^{\circ} \mathrm{N}-10^{\circ} \mathrm{S}\right)$ vertical EP flux normalized by the values at $100 \mathrm{hPa}$ and (c),(d) the zonal acceleration due to the EP-flux divergence $\left(\mathrm{cm} \mathrm{s}^{-1}\right.$ day $\left.^{-1}\right)$ during the QBO (a),(c) westerly and (b),(d) easterly phases as a function of the zonal phase speed. The white line represents the zonal mean zonal wind $\left(\mathrm{m} \mathrm{s}^{-1}\right)$.

waves with phase speeds between 30 and $60 \mathrm{~m} \mathrm{~s}^{-1}$ force the westerly shear zone associated with the semiannual oscillation (Fig. 8d), which, on average, is located around $2 \mathrm{hPa}$ in the 209 months defined as QBO easterly phase.

During the QBO easterly phase, the wave forcing of the easterly jet is weaker than the wave forcing of the westerly jet during the QBO westerly phase (cf. Figs. $8 \mathrm{c}, \mathrm{d})$. Integrated from 30 to $10 \mathrm{hPa}$, the difference amounts to $30 \%$ of the westerly wave forcing (not shown), which is about the same as the difference between the easterly and westerly wave momentum reaching $30 \mathrm{hPa}$ (cf. Figs. 7d,f).

Figure 9 shows the distribution of the wave forcing $\left(\nabla \cdot\left[F_{y}, F_{z}\right]\right)$ among bins of 10 zonal wavenumbers during the QBO westerly and easterly phase, integrated over frequencies ranging from 0 to $0.5 \mathrm{cpd}$ and from 0.5 to $2 \mathrm{cpd}$ as a function the zonal wavenumber and integrated from 30 to $10 \mathrm{hPa}$ to include all levels with considerable wave forcing during the respective QBO phases. Westerly waves $(k>0)$ with frequencies lower than $0.5 \mathrm{cpd}$ 

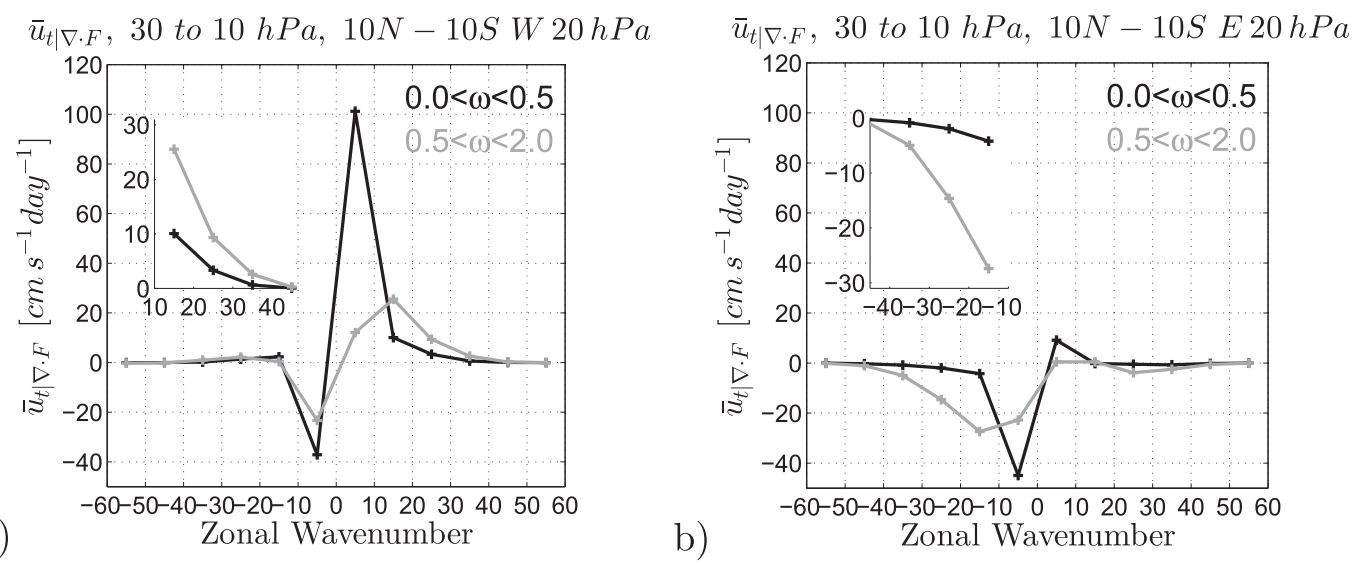

FIG. 9. Latitudinal-mean $\left(10^{\circ} \mathrm{N}-10^{\circ} \mathrm{S}\right)$ zonal wind tendency due to the divergence of the EP flux integrated from 30 to $10 \mathrm{hPa}\left(\mathrm{m} \mathrm{s}^{-1} \mathrm{day}^{-1}\right)$ during the QBO (a) westerly and (b) easterly phase. The tendency has been integrated over frequencies ranging from 0 to 0.5 (black), 0.5 to 1 (dark gray), and 1 to $2 \mathrm{cpd}$ (light gray). The small boxes show closeups of the zonal wind tendency at the respective wavenumbers. Negative wavenumbers indicate easterly waves.

(black line in Fig. 9a) and zonal wavenumbers lower than 10 (the spectral range of Kelvin waves) contribute most to the forcing of the QBO westerly jet (Fig. 9a). At wavenumbers between +10 and +30 , the largest contribution to the QBO westerly jet's forcing comes from waves with frequencies between 0.5 and 2 cpd (gray line in Fig. 9a). The easterly waves' tendencies in Fig. 9a are partly due to the inclusion of the forcing around the core of the QBO easterly jet at $30 \mathrm{hPa}$ in the vertical integral from 30 to $10 \mathrm{hPa}$ and partly due to the buildup of downward vertical EP flux around the zero wind line at $20 \mathrm{hPa}$ (Fig. 8a), which draws momentum from the flow. The origin of this peak is still investigated but could be due to waves with easterly phase speeds with respect to the ground, but westerly intrinsic phase speeds at their level of origin. Such waves have negative vertical EP flux and could become dominant after the bulk of easterly waves with also easterly intrinsic phase speeds has been filtered by the QBO easterly jet in the lower stratosphere. The masking of such waves is possible owing to the zonally uniform representation of the EP flux, which, however, can be zonally highly variable (Kawatani et al. 2010b).

The forcing of the QBO easterly jet is distributed more evenly among frequencies, even at low wavenumbers, and there is no canceling effect of westerly waves on the easterly forcing (Fig. 9b). The relative importance of easterly waves with high frequencies increases rapidly with wavenumber.

Based on model studies, Kawatani et al. (2010a) and Evan et al. (2012) showed that waves with zonal wavenumbers between 40 and 200 contribute about $60 \%$ and $80 \%$ to the total forcing of the QBO westerly and easterly jet, respectively. Based on observations, Ern et al. (2009a) also showed that small-scale waves have to account for $60 \%$ of the wave forcing of the QBO easterly jet. Figure 8 clearly demonstrates that in a GCM truncated at T63, the contribution of small-scale waves becomes negligible at wavenumbers larger than 40 . To account for the missing resolved wave drag, most GCMs parameterize the propagation and dissipation of smallerscale waves.

\section{c. Latitudinal structure of resolved wave forcing}

QBO dynamics are mostly studied based on latitudinal and zonal means. However, Kawatani et al. (2010b) showed that there are substantial variations of wave activity and wave forcing in both longitude and latitude. The latitudinal structure of the QBO forcing is also displayed in Fig. 10, which shows the latitudeheight cross section of the zonal wind and the zonal wind tendency due to the divergence of the EP flux carried by resolved waves during the QBO westerly and easterly phase (Figs. 10a-c and 10d-f, respectively). The forcing has been integrated over equatorial westerly waves with wavenumbers lower than 10 and frequencies lower than $0.5 \mathrm{cpd}$ (Figs. 10a,d), over westerly gravity waves with wavenumbers lower than 10 and frequencies larger than 0.5 , and with wavenumbers larger than 10 (Figs. 10b,e), and over all easterly waves (Figs. 10c,f). The latitudinal structures of the wind field and the forcing strongly depend on the season, and only months when the respective QBO phase occurs in June, July, or August (JJA) have been sampled. This criterion leaves 67 and 46 individual months for the QBO westerly and easterly phases, respectively. In December, January, and February, the latitudinal structure of the wind field and the forcing is mirrored with respect to the equator (not shown). 


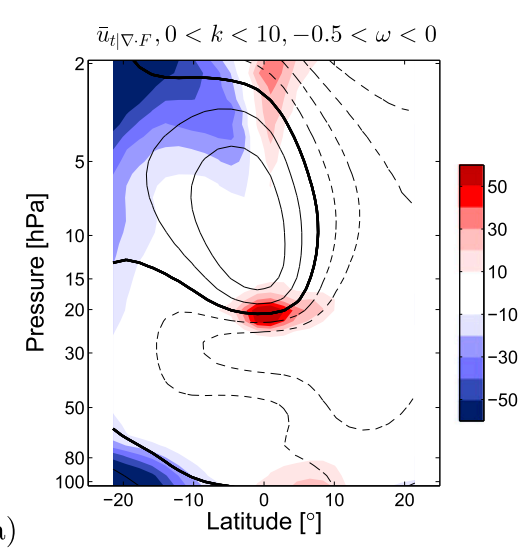

a)
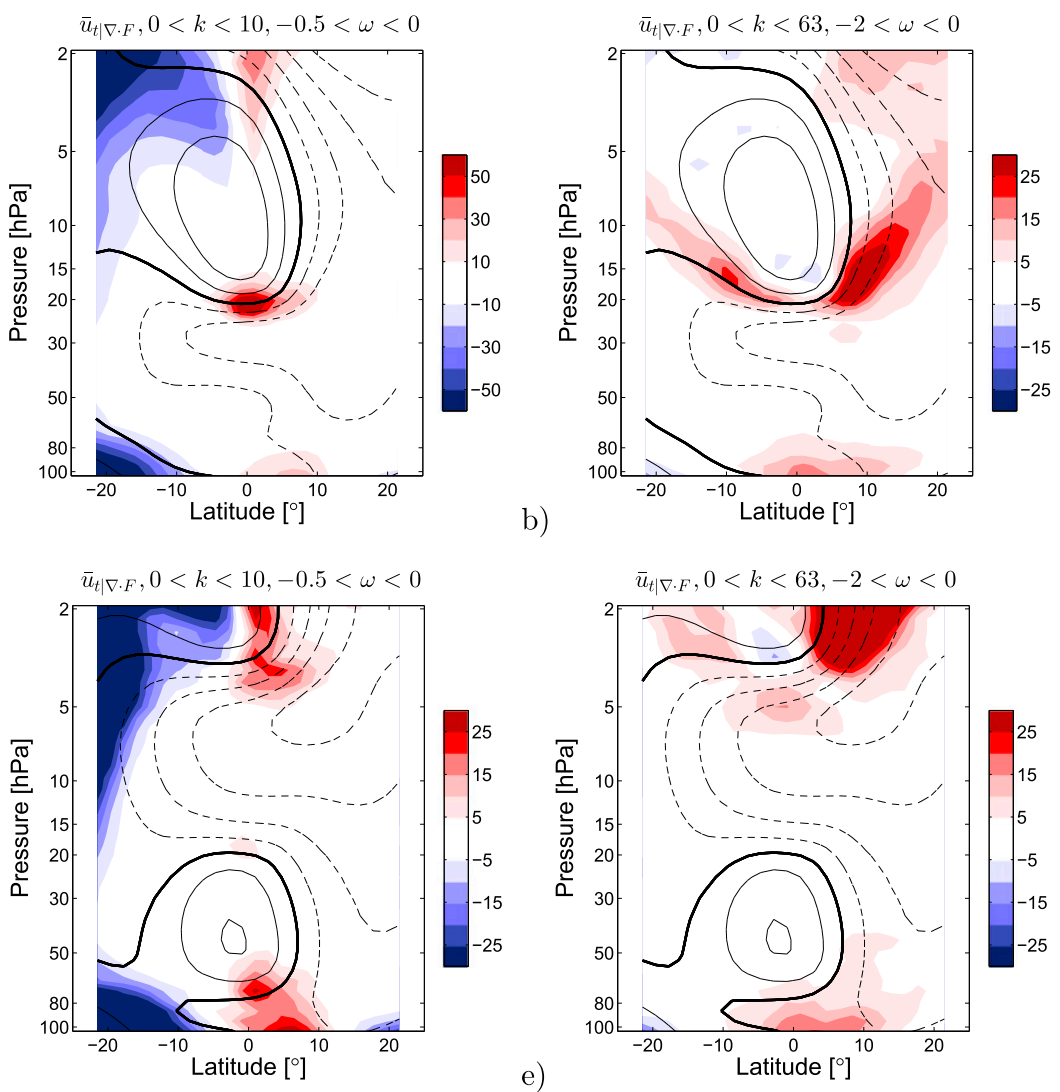

b)

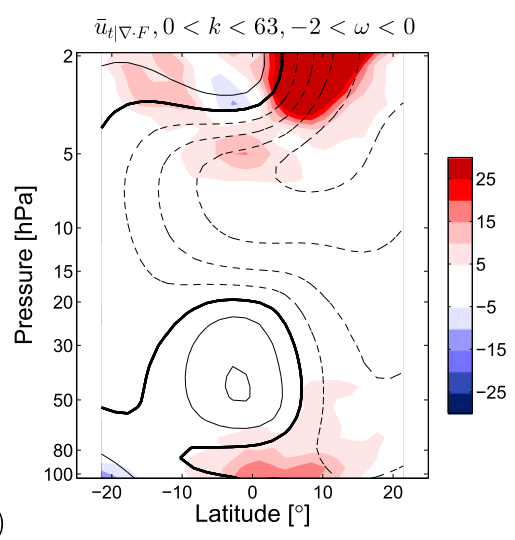

c)
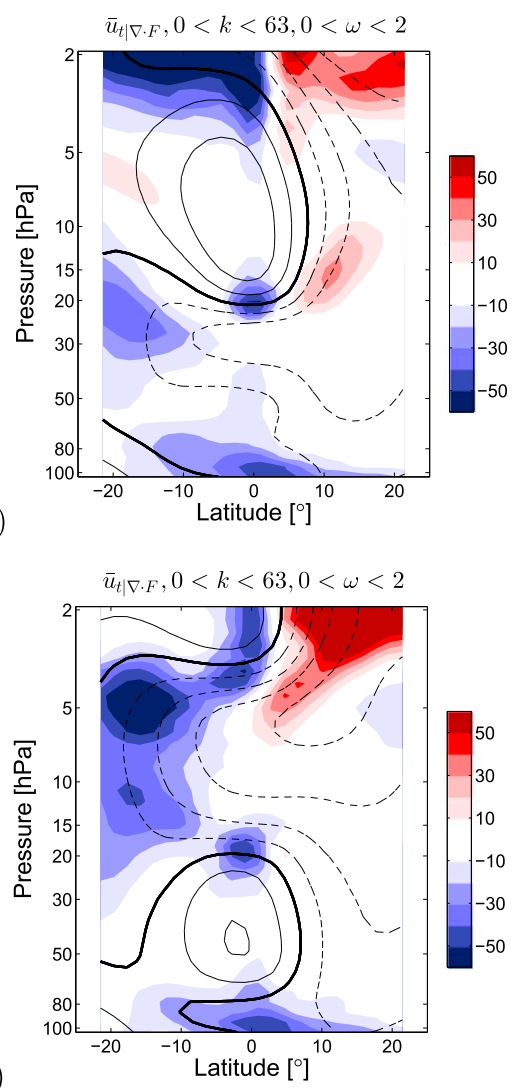

FIG. 10. Latitude-height cross section of the zonal mean zonal wind $\left(\mathrm{m} \mathrm{s}^{-1}\right.$; contour interval $\left.10 \mathrm{~m} \mathrm{~s}^{-1}\right)$ and the resolved wave forcing ( $\mathrm{cm} \mathrm{s}^{-1}$ day $^{-1}$; shading) in months when the QBO (a)-(c) westerly and (d)-(f) easterly phases occur in June, July, or August. Westerly (easterly) winds are drawn as solid (dashed) lines. The thick black contour indicates the zero wind line. The wave forcing has been integrated (a),(d) over equatorial westerly waves with wavenumbers lower than 10 and frequencies lower than $0.5 \mathrm{cpd}$, (b),(e) over westerly gravity waves with wavenumbers lower than 10 and frequencies larger than $0.5 \mathrm{cpd}$ and with wavenumbers larger than 10 , and (c), (f) over all easterly waves.

Consistent with the structure of Kelvin waves, which have a single maximum at the equator that decays toward the poles, the forcing of the QBO westerly jet due to equatorial westerly waves concentrates in a narrow band from $10^{\circ} \mathrm{N}$ to $10^{\circ} \mathrm{S}$ (Figs. 10a,d). The forcing due to westerly gravity waves is strongest away from the equator at the flanks of the QBO westerly jet, which is again consistent with the latitudinal structure of the gravity waves. Opposite to Kelvin waves, these have node 0,2 , or 4 structures with at least one relative minimum of the wave-induced perturbations at the equator and maximal wave-induced perturbations at higher latitudes (Matsuno 1966; Kiladis et al. 2009). The westerly gravity wave's forcing is stronger in the summer hemisphere (Figs. 10b, e). This can be explained by stronger convective activity in the summer hemisphere and, hence, stronger excitation of gravity waves (not shown) and the circumstance that the zonal wind in the summer hemisphere is easterly above $500 \mathrm{hPa}$, which facilitates the propagation of westerly waves (Fig. 10).
Easterly waves impose a westerly forcing along the flank of the westerly jet in the summer hemisphere (Fig. 10c), mostly owing to the divergence of the horizontal momentum flux (not shown) and, thus, to the meridional propagation of the easterly waves. During the QBO easterly phase, easterly waves force the easterly jet at its lowermost edge close to the equator (Fig. 10f) and, much stronger, over the whole depth of the easterly jet in the winter hemisphere. Since the convective wave sources are weaker in the winter than in the summer hemisphere (not shown), this subtropical maximum has to be due to the enhanced excitation of easterly waves that propagate equatorward and the circumstance that zonal wind between $10^{\circ} \mathrm{S}$ and $20^{\circ} \mathrm{S}$ is westerly from 500 to $50 \mathrm{hPa}$ in the selected season, which facilitates the propagation of easterly waves.

\section{d. Resolved wave forcing during a quasi-biennial cycle}

To investigate the dependence of the resolved wave forcing on the altitude of the QBO jets, a series of 


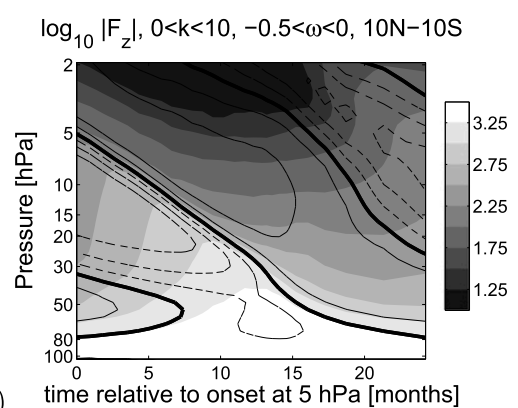

a)

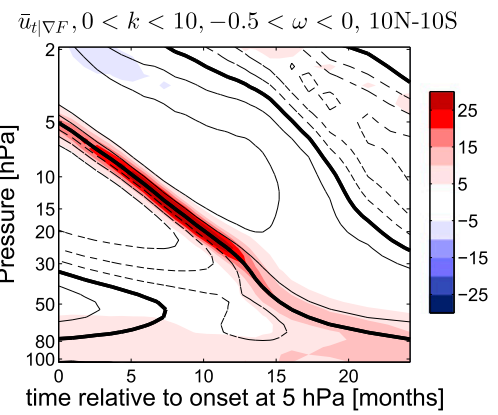

d)

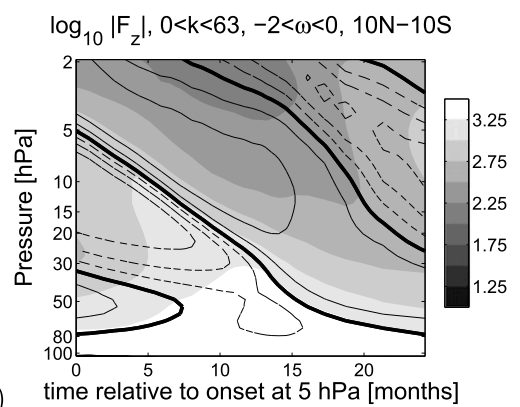

b)

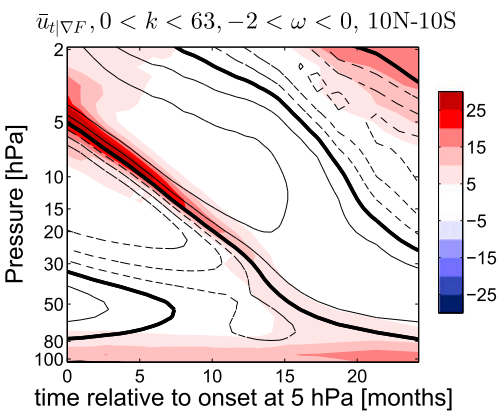

e)

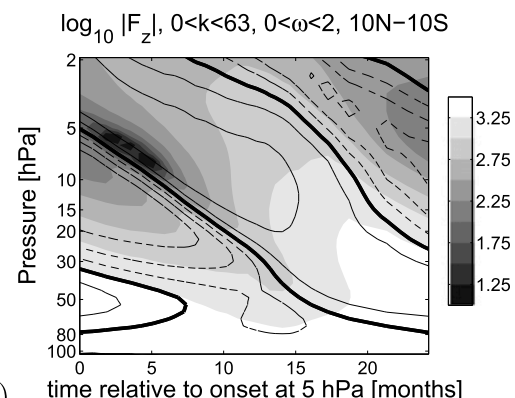

c)

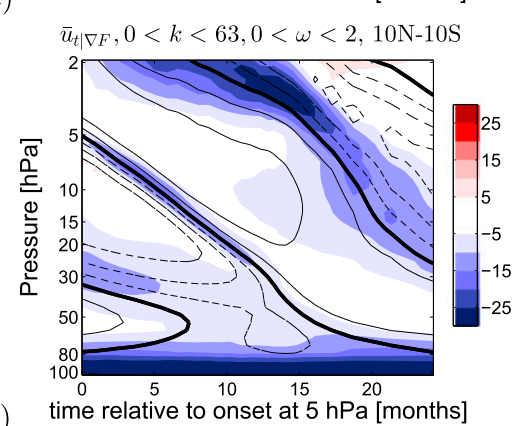

FIG. 11. Altitude-time cross section of the zonal mean zonal wind $\left(\mathrm{ms}^{-1}\right.$; contour interval $\left.10 \mathrm{~m} \mathrm{~s}^{-1}\right)$, the vertical EP flux $\left[\log _{10}\left(\mathrm{~kg} \mathrm{~m}^{-1} \mathrm{~s}^{-2}\right)\right.$; shading in (a)-(c)] and the resolved wave forcing [ $\mathrm{cm} \mathrm{s}^{-1}$ day $^{-1}$; shading in (d)-(f)]. Each month is representative of a composite including all months when the onset of the QBO westerly jet is located at the respective level between 5 and $100 \mathrm{hPa}$. Westerly (easterly) winds are drawn as solid (dashed) lines. The thick black contour indicates the zero wind line. The EP flux and the wave forcing have been integrated (a),(d) over equatorial westerly waves with wavenumbers lower than 10 and frequencies lower than $0.5 \mathrm{cpd}$, (b),(e) over westerly gravity waves with wavenumbers lower than 10 and frequencies larger than $0.5 \mathrm{cpd}$ and with wavenumbers larger than 10 , and (c),(f) over all easterly waves.

composites including only months when the zonal wind turns from easterly to westerly, such as presented for the phase transition at $20 \mathrm{hPa}$ in Fig. $8 \mathrm{c}$, have been computed for each of the 28 model levels between 5 and $80 \mathrm{hPa}$. The occurrence of the phase transition is the only sampling criterion. In Fig. 11, which shows the mean zonal wind, the vertical EP flux (Figs. 11a-c) and the resolved wave forcing (Figs. 11d-f) for all these composites, the composites are sorted in such a way as to start and end with the onset of the QBO westerly jet at 5 and $80 \mathrm{hPa}$, respectively, which, thus, creates the impression of a continuous QBO westerly jet descending from the upper to the lower stratosphere. The $x$ axis indicates the average time that the QBO westerly jet needs to descend from $5 \mathrm{hPa}$ to the respective level. As for Fig. 10, the EP flux and the zonal acceleration due to resolved waves have been integrated over equatorial westerly waves with wavenumbers lower than 10 and frequencies lower than $0.5 \mathrm{cpd}$ (Fig. 11a), over westerly gravity waves with wavenumbers lower than 10 and frequencies larger than $0.5 \mathrm{cpd}$ and with wavenumbers larger than 10 (Fig. 11b), and over all easterly waves (Fig. 11c).

Figures 11a and $11 \mathrm{~b}$ show that-owing to the continuous radiative attenuation-the vertical EP flux carried by westerly waves decreases continuously with increasing distance between the tropopause and the zero wind line associated with the onset of the QBO westerly jet. This becomes especially obvious between months 7 and 15 , when the zonal wind is easterly between 100 and $30 \mathrm{hPa}$, and, hence, does not provide critical levels for westerly waves. Within this easterly flow, the EP flux carried by easterly waves decreases continuously with height (Fig. 11c). However, within the QBO westerly jet, the EP flux carried by easterly waves stays relatively constant (e.g., months 15-25 in Fig. 11c).

Figure $11 \mathrm{~d}$ shows that, averaged from $10^{\circ} \mathrm{N}$ to $10^{\circ} \mathrm{S}$, the forcing due to equatorial westerly waves is strongest if the onset (lower boundary) of the QBO westerly jet is located between 30 and $10 \mathrm{hPa}$. If the onset of the QBO westerly jet is located at higher altitudes, the equatorial waves are partly filtered by the QBO westerly jet of the previous quasi-biennial cycle still present in the lower stratosphere. If the onset of the QBO westerly jet is located below $30 \mathrm{hPa}$, the westerly jet is weaker than at higher altitudes, and, thus, fewer waves are Doppler shifted to intrinsic phase speeds and vertical wavelengths suitable for efficient wave dissipation. Further, the values in Fig. 11 are not density corrected. Hence, the same amount of wave momentum deposition results 
in stronger zonal acceleration at high altitudes with relatively low air densities.

The westerly gravity waves with frequencies higher than $0.5 \mathrm{cpd}$ and wavenumbers lower than 10 , which are included in the forcing shown in Fig. 11e, are generally very fast and, thus, less affected by the lower-level QBO westerly jet than equatorial waves with slower phase speed. As the wave filtering at low altitudes is less pronounced, the forcing due to westerly gravity waves increases with increasing altitude of the onset of the QBO westerly jet due do the decrease of density with altitude (Fig. 11e).

Above $80 \mathrm{hPa}$, the forcing due to westerly waves is limited to a narrow vertical band around the onset of the QBO westerly jet (Figs. 11d,e). Easterly waves, however, deposit easterly wave momentum at the zero wind line associated with the onset of both the QBO easterly and westerly jets (Fig. 11f). The forcing increases with altitude, probably owing to the decrease of density with height and, in part, to the latitudinal propagation of extratropical large-scale easterly waves.

Note that because of the decrease of density with altitude, the zonal wind tendency $\left(10^{-2} \mathrm{~m} \mathrm{~s}^{-1}\right)$ can increase with increasing altitude of the zero wind line (Figs. 11d-f), even though the EP flux decreases because of wave filtering below (Figs. 11a-c). However, because of this wave filtering, the actual momentum tendency due to wave dissipation $\left(\mathrm{kg} \mathrm{m}^{-2} \mathrm{~s}^{-1}\right)$ strongly decreases with altitude (not shown).

\section{The zonal momentum balance}

The zonal wind tendency equation does not only include resolved wave drag. Following Andrews et al. (1987), the TEM momentum equation states that

$$
\begin{aligned}
\bar{u}_{t}= & \bar{v}^{*}\left[f-(a \cos \phi)^{-1}(\bar{u} \cos \phi)_{\phi}\right]-\bar{w}^{*} \bar{u}_{z} \\
& +\left(\rho_{0} a \cos \phi\right)^{-1} \nabla \cdot \mathbf{F}+\bar{u}_{t \mid \mathrm{GWD}},
\end{aligned}
$$

where $\bar{v}^{*}$ and $\bar{w}^{*}$ are the meridional and vertical residual mean winds and $\bar{u}_{t \mid \mathrm{GWD}}$ represents the parameterized gravity wave drag. The gravity wave drag has only been stored during the first 30 years of the MPIESM piControl run, and the results presented next are based on this period. However, the averages of the resolved wave drag and the advective terms do not change significantly if computed over the first 500 years of the piControl run.

Figure 12 shows profiles of the zonal wind and the terms of the momentum balance for the QBO westerly and easterly phase. To make the results comparable to Giorgetta et al. (2006), the values are latitudinally
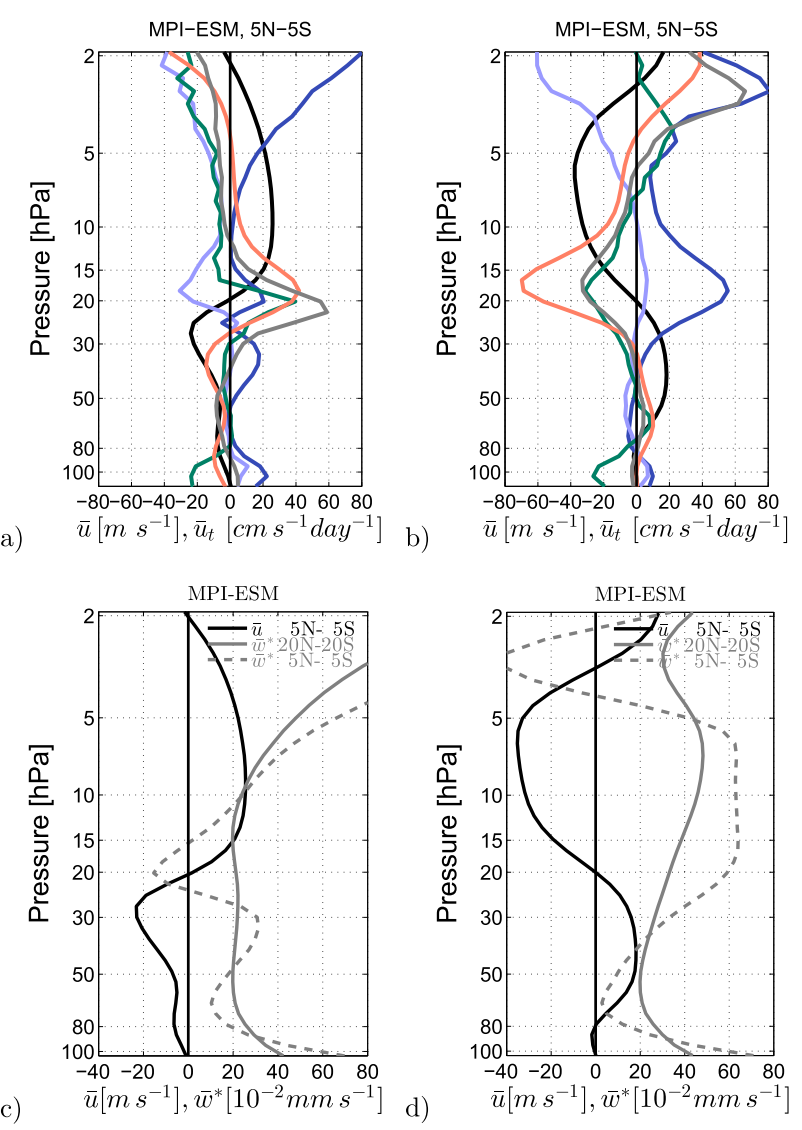

FIG. 12. (top) Latitudinal-mean $\left(5^{\circ} \mathrm{N}-5^{\circ} \mathrm{S}\right)$ profile of the zonal wind ( $\mathrm{m} \mathrm{s}^{-1}$, black), the zonal wind tendency $\left(\mathrm{cm} \mathrm{s}^{-1}\right.$ day $^{-1}$; gray), and the zonal wind tendency $\left(\mathrm{cm} \mathrm{s}^{-1} \mathrm{day}^{-1}\right)$ due to resolved waves (green), parameterized waves (orange), vertical advection (dark blue), and horizontal advection (light blue) during the QBO (a) westerly and (b) easterly phases. (bottom) The latitudinal-mean profile of the zonal wind $\left(\mathrm{m} \mathrm{s}^{-1}, 5^{\circ} \mathrm{N}-5^{\circ} \mathrm{S}\right.$, black) and the residual vertical motion $\left(10^{-2} \mathrm{~mm} \mathrm{~s}^{-1}\right)$ averaged from $20^{\circ} \mathrm{N}$ to $20^{\circ} \mathrm{S}$ (solid gray) and from $5^{\circ} \mathrm{N}$ to $5^{\circ} \mathrm{S}$ (dashed gray) during the QBO (c) westerly and (d) easterly phase.

averaged from $5^{\circ} \mathrm{N}$ to $5^{\circ} \mathrm{S}$. The total zonal acceleration at the zero wind line associated with the onset of the QBO westerly jet at $20 \mathrm{hPa}$ amounts to $0.6 \mathrm{~m} \mathrm{~s}^{-1}$ (gray line in Fig. 12a). Within the narrow layer where longwave radiative damping results in pronounced resolved wave momentum deposition, the resolved and the parameterized wave forcing (green and orange line in Fig. 12a, respectively) are about equally strong $\left(0.4 \mathrm{~m} \mathrm{~s}^{-1}\right)$. However, the parameterized waves mainly give momentum to the flow where the zonal phase speed closely matches the background zonal wind. Hence, the parameterized wave forcing extends farther into the QBO westerly jet, where faster waves meet critical levels. Above the zero wind line, this parameterized acceleration mostly strengthens the QBO jet and, thus, contributes to the QBO's amplitude rather than its downward propagation 
rate. The vertical advection around the zero wind line is positive and amounts to about one-quarter of the total wave forcing (dark blue line in Fig. 12a).

Figure $12 \mathrm{c}$ shows the profiles of the tropical and equatorial vertical velocity (averaged from $20^{\circ} \mathrm{N}$ to $20^{\circ} \mathrm{S}$ and from $5^{\circ} \mathrm{N}$ to $5^{\circ} \mathrm{S}$, respectively) for the QBO westerly phase. From 80 to $15 \mathrm{hPa}$, the tropical vertical upwelling (solid gray line) amounts to $0.20 \mathrm{~mm} \mathrm{~s}^{-1}$. The secondary circulation induced by the QBO westerly jet, which is directed downward in the equatorial area, strongly reduces the vertical velocity and turns the equatorial vertical motion (dashed gray line) at $20 \mathrm{hPa}$ downward. Hence, the QBO westerly jet advects itself to lower altitudes.

The total zonal acceleration at the zero wind line associated with the onset of the QBO easterly jet at $20 \mathrm{hPa}$ amounts to $0.3 \mathrm{~m} \mathrm{~s}^{-1}$ (Fig. 12b). The forcing from parameterized waves is about twice that of the resolved waves. Compared to parameterized westerly waves, parameterized easterly waves are less filtered between the source level at $700 \mathrm{hPa}$ and the lowermost stratosphere (not shown) in MPI-ESM, which has also been reported by Kim et al. (2013) for another GCM. Hence, compared to the QBO westerly jet, the parameterized wave forcing is almost 2 times larger at the onset of the QBO easterly jet (cf. orange lines in Figs. 12a and 12b). The QBO easterly jet strengthens the upward motion in the equatorial area and, because of its larger latitudinal extent, also over the whole tropics (Fig. 12d). Between 30 and $15 \mathrm{hPa}$, the average tropical and equatorial vertical velocities amount to 0.3 and $0.5 \mathrm{~mm} \mathrm{~s}^{-1}$, respectively. Hence, the vertical advection at the onset of the QBO easterly jet is largely positive and works against its downward propagation (Fig. 12d).

A zonal momentum balance for the two QBO phases shown in Fig. 12 has been presented by Giorgetta et al. (2006) based on the global atmosphere model MAECHAM5 truncated at T42 (their Fig. 10) and by Evan et al. (2012) based on the Weather Research and Forecasting (WRF) tropical channel model with a resolution of $37 \mathrm{~km}$ (their Fig. 10). Compared to Giorgetta et al. (2006), the wave forcing at the zero wind line (resolved plus-or-minus parameterized waves) is about $60 \%$ stronger in MPI-ESM than in MAECHAM5 $\left(0.8 \mathrm{~m} \mathrm{~s}^{-1}\right.$ day $^{-1}$ compared to $0.5 \mathrm{~m} \mathrm{~s}^{-1}$ day $\left.^{-1}\right)$ during the QBO westerly phase. This occurs for multiple reasons. First, the source strength of the Hines gravity wave scheme is stronger in MPI-ESM, which strengthens the parameterized wave forcing. Second, MPI-ESM has a larger spectral truncation and resolves slightly more waves that contribute to the resolved wave forcing. Third, the QBO jets are $10 \mathrm{~m} \mathrm{~s}^{-1}$ stronger in MPI-ESM than in Giorgetta et al. (2006). Hence, a larger spectrum of waves and in particular of parameterized waves meets critical levels and contributes to the forcing. However, the slightly larger total acceleration at the zero wind line in MPI-ESM causes the jets to descend more quickly than in MAECHAM5 (not shown). Compared to Evan et al. (2012), the forcing from small-scale waves (parameterized waves in MPI-ESM) is about equal; however, the large-scale wave forcing (resolved waves in MPI-ESM) and the total forcing are stronger in MPI-ESM.

\section{Summary and discussion}

This study presented an in-depth analysis of the resolved wave forcing of the QBO in the Max Planck Institute Earth System model (MPI-ESM), which spectrally truncates at T63. Extending the work on the QBO forcing by Giorgetta et al. (2006), a spectral analysis of tropical precipitation as a proxy for wave sources, the temperature variance, and the EP flux in the stratosphere as performed for high-resolution models by Kawatani et al. (2010a) and Evan et al. (2012) documents the processes of wave generation, propagation, and forcing for the applied course-resolution model, thus setting a reference for the current generation of operational GCMs. Special emphasis is given to the dynamical and physical processes involved in the radiative and diffusive damping of resolved waves.

The T63 truncation of MPI-ESM limits this study to large-scale waves, which, compared to TRMM observations, have a realistic precipitation variance at wavenumbers lower than 20 and frequencies lower than $0.5 \mathrm{cpd}$. At these large scales and low frequencies, precipitation is mostly organized in Matsuno-type (Matsuno 1966) Kelvin waves, mixed Rossby-gravity waves, and n0 westerly waves, which is a common feature in today's GCMs (Lott et al. 2014). However, the model underestimates the precipitation variance at wavenumbers large than 20 and frequencies higher than $0.5 \mathrm{cpd}$, which suggests that also the QBO wave forcing at these scales is too low and explains the need for gravity wave parameterizations in order to transport sufficient momentum into the stratosphere to force the QBO.

MPI-ESM shows the expected loss of spectral variance and wave momentum flux due to the filtering effect of the QBO easterly and westerly jets, which have been reported by Ern and Preusse (2009b), Yang et al. (2011), and Evan et al. (2012). The study linked the observed loss of spectral power to the Doppler shift of the waves' vertical wavelength and an associated increase of the waves' amplitude, both leading to increased wave damping. The longwave radiative damping of the wave-induced temperature perturbation is the dominant damping mechanism for large-scale equatorial waves, which, in accordance with high-resolution studies, 
contribute about $40 \%$ and $50 \%$ to the total resolved wave forcing of the QBO easterly and westerly jets, respectively. Horizontal diffusion of the zonal wind perturbation dissipates waves with zonal wavenumbers larger than 10 and frequencies larger than $0.5 \mathrm{cpd}$. In this respect, it is important to note that the time scales of the radiative wave damping decrease with zonal phase speed, which is to be expected from physical considerations, while horizontal diffusion increases mostly with the zonal wavenumber. It is found that the horizontal diffusion scheme efficiently suppresses waves with wavenumbers larger than 20 , independently of the wave's frequencies. Hence, the suppressed spectrum, though resolved in the model, does not contribute considerably to the QBO's forcing.

The different damping mechanisms also manifest in the profiles of the vertical EP flux and the wave-induced zonal wind tendency. The forcing of the QBO westerly jet is confined to a thin vertical layer around the zero wind line, where most Kelvin waves do not meet critical levels but have sufficiently low vertical wavelengths to be efficiently damped by longwave radiation, and waves with phase speeds considerably faster than the QBO westerly jet can contribute to its forcing. Easterly waves, however, are mostly damped by horizontal diffusion at critical levels, which spreads the easterly wave forcing from the zero wind line to the core of the easterly jets at higher altitudes.

The latitudinal dependence of the wave forcing found by Kawatani et al. (2010b) is also evident in MPI-ESM. The westerly forcing due to large-scale equatorial waves is confined to a narrow band around the equator, while the forcing due to smaller-scale waves with higher frequencies is strongest off the equator at the edges of the westerly jet and strongest in the summer hemisphere. This structure is consisted with the latitudinal structure of large- and small-scale waves proposed and shown by Matsuno (1966) and Kiladis et al. (2009). The easterly wave forcing of the QBO easterly jet is strongest in the winter hemisphere at the upper margin of the easterly jet, partly because of equatorward propagation of extratropical easterly waves and partly because of westerly winds in the lower stratosphere, which facilitate the propagation of easterly waves.

The investigated model run covers 209 quasi-biennial cycles, which gives the unique opportunity to study the mean evolution of the QBO forcing during a whole cycle. It is found that because large-scale waves are mostly damped by radiation also away from critical levels, the EP flux that they carry diverges even when the background flow is opposite to their propagation direction and, therefore, would be favorable for their upward propagation. Hence, the waves' contribution to the forcing of the QBO jets decreases with increasing altitudes of the zero wind line when the waves propagate through an increasingly deep layer in the lower stratosphere. Waves with wavenumbers much smaller than the truncation limit no longer contribute substantially to the QBO's forcing at high altitudes.

As already proposed by Takahashi (1999), horizontal diffusion effectively limits the modeled wave activity in the stratosphere. However, because of observational limitations, it is difficult to validate the simulated strength of resolved stratospheric wave field. Increasing the horizontal resolution of the model and adjusting the applied horizontal diffusion should allow for estimating the constraints on wave propagation in the low-resolution version.

Acknowledgments. We acknowledge the MPI-ESM modeling group for technical support. We thank Elisa Manzini and Joan Alexander for fruitful discussions. Computational resources to conduct the CMIP5 experiments were made available by Deutsches Klimarechenzentrum (DKRZ) through support from the Bundesministerium für Bildung und Forschung (BMBF).

\section{REFERENCES}

Andrews, D., J. Holton, and C. B. Leovy, 1987: Middle Atmosphere Dynamics. 1st ed. Academic Press, 489 pp.

Anstey, J. A., and T. G. Shepherd, 2014: High-latitude influence of the quasi-biennial oscillation. Quart. J. Roy. Meteor. Soc., 140, 1-21, doi:10.1002/qj.2132.

Baldwin, M. P., 2005: Tropical stratospheric zonal winds in ECMWF ERA-40 reanalysis, rocketsonde data, and rawinsonde data. Geophys. Res. Lett., 32, L09806, doi:10.1029/ 2004 GL022328.

Geophys., 39, 179-229, doi:10.1029/1999RG000073.

Canziani, P. O., and J. R. Holton, 1998: Kelvin waves and the quasibiennial oscillation: An observational analysis. J. Geophys. Res., 103 (D24), 31 509-31 521, doi:10.1029/1998JD200021.

Crueger, T., C. Hohenegger, and W. May, 2013: Tropical precipitation and convection changes in the Max Planck Institute Earth system model (MPI-ESM) in response to $\mathrm{CO}_{2}$ forcing. J. Adv. Model. Earth Syst., 5, 85-97, doi:10.1002/jame.20012.

Dunkerton, T. J., 1991: Nonlinear propagation of zonal winds in an atmosphere with Newtonian cooling and equatorial wavedriving. J. Atmos. Sci., 48, 236-263, doi:10.1175/ 1520-0469(1991)048<0236:NPOZWI $>2.0$. CO;2.

Ern, M., and P. Preusse, 2009a: Quantification of the contribution of equatorial Kelvin waves to the QBO wind reversal in the stratosphere. Geophys. Res. Lett., 36, L21801, doi:10.1029/ 2009GL040493.

- , and $-2009 \mathrm{~b}$ : Wave fluxes of equatorial Kelvin waves and QBO zonal wind forcing derived from SABER and ECMWF temperature space-time spectra. Atmos. Chem. Phys. Discuss., 9, 5623-5677, doi:10.5194/acpd-9-5623-2009.

- — - M. Krebsbach, M. G. Mlynczak, and J. M. Russell, 2008: Equatorial wave analysis from SABER and ECMWF temperatures. Atmos. Chem. Phys., 8, 845-869, doi:10.5194/ acp-8-845-2008. 
— H.-K. Cho, P. Preusse, and S. D. Eckermann, 2009a: Properties of the average distribution of equatorial Kelvin waves investigated with the GROGRAT ray tracer. Atmos. Chem. Phys., 9, 7973-7995, doi:10.5194/acp-9-7973-2009.

— C. Lehmann, M. Kaufmann, and M. Riese, 2009b: Spectral wave analysis at the mesopause from SCIAMACHY airglow data compared to SABER temperature spectra. Ann. Geophys., 27, 407-416, doi:10.5194/angeo-27-407-2009.

Evan, S., M. J. Alexander, and J. Dudhia, 2012: WRF simulations of convectively generated gravity waves in opposite QBO phases. J. Geophys. Res., 117, D12117, doi:10.1029/2011JD017302.

Fels, S. B., 1982: A parameterization of scale-dependent radiative damping rates in the middle atmosphere. J. Atmos. Sci., 39, 1141-1152.

Fritts, D., and M. J. Alexander, 2003: Gravity wave dynamics and effects in the middle atmosphere. Rev. Geophys., 41, 1003, doi:10.1029/2001RG000106.

Garcia, R. R., and R. Lieberman, 2005: Large-scale waves in the mesosphere and lower thermosphere observed by SABER. J. Atmos. Sci., 62, 4384-4399, doi:10.1175/JAS3612.1.

Giorgetta, M. A., L. Bengtsson, and K. Arpe, 1999: An investigation of $\mathrm{QBO}$ signals in the east Asian and Indian monsoon in GCM experiments. Climate Dyn., 15, 435-450, doi:10.1007/s003820050292.

_ - E. Manzini, and E. Roeckner, 2002: Forcing of the quasibiennial oscillation from a broad spectrum of atmospheric waves. Geophys. Res. Lett., 29, 1245, doi:10.1029/2002GL014756.

$-, \ldots,-$, M. Esch, and L. Bengtsson, 2006: Climatology and forcing of the quasi-biennial oscillation in the MAECHAM5 model. J. Climate, 19, 3882-3901, doi:10.1175/JCLI3830.1.

— , and Coauthors, cited 2012: CMIP5 simulations of the Max Planck Institute for Meteorology (MPI-M) based on the MPI-ESM-MR model: The piControl experiment, served by ESGF. World Data Center for Climate. [Available online at http://eudat-jmd.dkrz.de/dataset/dca61118-7c16-5751-97b5125d09cdc648.]

—_, and Coauthors, 2013: Climate and carbon cycle changes from 1850 to 2100 in MPI-ESM simulations for the Coupled Model Intercomparison Project phase 5 (2013). J. Adv. Model. Earth Syst., 5, 572-597, doi:10.1002/jame.20038.

Hines, C. O., 1997a: Doppler-spread parameterization of gravitywave momentum deposition in the middle atmosphere. Part 1: Basic formulation. J. Atmos. Sol. Terr. Phys., 59, 371-386, doi:10.1016/S1364-6826(96)00079-X.

— $1997 \mathrm{~b}$ : Doppler-spread parameterization of gravity-wave momentum deposition in the middle atmosphere. Part 2: Broad and quasi monochromatic spectra, and implementation. J. Atmos. Sol. Terr. Phys., 59, 387-400, doi:10.1016/ S1364-6826(96)00080-6.

Hitchcock, P., T. G. Shepherd, and S. Yoden, 2010: On the approximation of local and linear radiative damping in the middle atmosphere. J. Atmos. Sci., 67, 2070-2085, doi:10.1175/ 2009JAS3286.1.

Holton, J., and R. Lindzen, 1972: An updated theory for the quasibiennial cycle of the tropical stratosphere. J. Atmos. Sci., 29, 1076-1080, doi:10.1175/1520-0469(1972)029<1076: AUTFTQ $>2.0 . \mathrm{CO} ; 2$.

- , and H. Tan, 1980: The influence of the equatorial quasibiennial oscillation on the global circulation at $50 \mathrm{mb}$. J. At mos. Sci., 37, 2200-2208, doi:10.1175/1520-0469(1980)037<2200: TIOTEQ $>2.0 . \mathrm{CO} ; 2$.

Horinouchi, T., and Coauthors, 2003: Tropical cumulus convection and upward-propagating waves in middle- atmospheric GCMs. J. Atmos. Sci., 60, 2765-2782, doi:10.1175/ 1520-0469(2003)060<2765:TCCAUW $>2.0 . C O ; 2$.

Huffman, G. J., and Coauthors, 2007: The TRMM Multisatellite Precipitation Analysis (TMPA): Quasi-global, multiyear, combined-sensor precipitation estimates at fine scales. J. Hydrometeor., 8, 38-55, doi:10.1175/JHM560.1.

Jungclaus, J. H., and Coauthors, 2013: Characteristics of the ocean simulations in MPIOM, the ocean component of the MPIEarth system model. J. Adv. Model. Earth Syst., 5, 422-446, doi:10.1002/jame.20023.

Kawatani, Y., S. Watanabe, K. Sato, T. J. Dunkerton, S. Miyahara, and M. Takahashi, 2010a: The roles of equatorial trapped waves and internal inertia-gravity waves in driving the quasibiennial oscillation. Part I: Zonal mean wave forcing. J. Atmos. Sci., 67, 963-980, doi:10.1175/2009JAS3222.1.

,,,,,---- and,$- 2010 \mathrm{~b}$ : The roles of equatorial trapped waves and internal inertia-gravity waves in driving the quasi-biennial oscillation. Part II: Threedimensional distribution of wave forcing. J. Atmos. Sci., 67, 981-997, doi:10.1175/2009JAS3223.1.

Kiladis, G., M. Wheeler, P. Haertel, K. Straub, and P. Roundy, 2009: Convectively coupled equatorial waves. Rev. Geophys., 47, RG2003, doi:10.1029/2008RG000266.

Kim, J.-E., and M. J. Alexander, 2013: Tropical precipitation variability and convectively coupled equatorial waves on submonthly time-scales in reanalyses and TRMM. J. Climate, 26, 3013-3030, doi:10.1175/JCLI-D-12-00353.1.

Kim, Y.-H., A. C. Bushell, D. R. Jackson, and H.-Y. Chun, 2013: Impacts of introducing a convective gravity-wave parameterization upon the QBO in the Met Office Unified Model. Geophys. Res. Lett., 40, 1873-1877, doi:10.1002/grl.50353.

Krismer, T. R., M. A. Giorgetta, and M. Esch, 2013: Seasonal aspects of the quasibiennial oscillation in MPIESM and ERA40. J. Adv. Model. Earth Syst., 5, 406-421, doi:10.1002/jame.20024.

Liess, S., and M. A. Geller, 2012: On the relationship between QBO and distribution of tropical deep convection. J. Geophys. Res., 117, D03108, doi:10.1029/2011JD016317.

Lin, J., and Coauthors, 2006: Tropical intraseasonal variability in 14 IPCC AR4 climate models. Part I: Convective signals. J. Climate, 19, 2665-2690, doi:10.1175/JCLI3735.1.

Lindzen, R., and J. Holton, 1968: A theory of the quasi-biennial oscillation. J. Atmos. Sci., 25, 1095-1107, doi:10.1175/ 1520-0469(1968)025<1095:ATOTQB > 2.0.CO;2.

Lott, F., and Coauthors, 2014: Kelvin and Rossby-gravity wave packets in the lower stratosphere of some high-top CMIP5 models. J. Geophys. Res. Atmos., 119, 2156-2173, doi:10.1002/ 2013JD020797.

Manzini, E., and N. A. McFarlane, 1998: The effect of varying the source spectrum of a gravity wave parameterization in a middle atmosphere general circulation model. J. Geophys. Res., 103, 31 523-31 539, doi:10.1029/98JD02274.

_ , M. A. Giorgetta, M. Esch, L. Kornblueh, and E. Roeckner, 2006: The influence of sea surface temperatures on the northern winter stratosphere: Ensemble simulations with the MAECHAM5 model. J. Climate, 19, 3863-3881, doi:10.1175/ JCLI3826.1.

Matsuno, T., 1966: Quasi-geostrophic motions in the equatorial area. J. Meteor. Soc. Japan, 44, 25-43.

Mauritsen, T., and Coauthors, 2012: Tuning the climate of a global model. J. Adv. Model. Earth Syst., 4, M00A01, doi:10.1029/ 2012MS000154. 
Möbis, B., and B. Stevens, 2012: Factors controlling the position of the Intertropical Convergence Zone on an aquaplanet. J. $A d v$. Model. Earth Syst., 4, M00A04, doi:10.1029/2012MS000199.

Mote, P. W., and Coauthors, 1996: An atmospheric tape recorder: The imprint of tropical tropopause temperatures on stratospheric water vapor. J. Geophys. Res., 101, 3989 4006, doi:10.1029/95JD03422.

Orr, A., P. Bechtold, J. Scinocca, M. Ern, and M. Janiskova, 2010: Improved middle atmosphere climate and forecasts in the ECMWF model through a nonorographic gravity wave drag parameterization. J. Climate, 23, 5905-5926, doi:10.1175/ 2010JCLI3490.1.

Ortland, D. A., and M. J. Alexander, 2011: Solutions to the vertical structure equation for simple models of the tropical troposphere. J. Atmos. Sci., 68, 2061-2072, doi:10.1175/2011JAS3719.1.

Plumb, R., 1977: The interaction of two internal waves with the mean flow: Implications for the theory of the quasibiennial oscillation. J. Atmos. Sci., 34, 1847-1858, doi:10.1175/ 1520-0469(1977)034<1847:TIOTIW>2.0.CO;2.

Punge, H. J., and M. A. Giorgetta, 2008: Net effect of the QBO in a chemistry climate model. Atmos. Chem. Phys., 8, 6505-6525, doi:10.5194/acp-8-6505-2008.

Raddatz, T. J., and Coauthors, 2007: Will the tropical land biosphere dominate the climate carbon cycle feedback during the twenty-first century? Climate Dyn., 29, 565-574, doi:10.1007/ s00382-007-0247-8.

Roeckner, E., and Coauthors, 2003: The atmospheric general circulation model ECHAM5, Part I: Model description. Max Planck Institute for Meteorology Tech. Rep. 349, 140 pp. [Available online at http://www.mpimet.mpg.de/fileadmin/ publikationen/Reports/max_scirep_349.pdf.]

Sato, K., and T. J. Dunkerton, 1997: Estimates of momentum flux associated with equatorial Kelvin and gravity waves. J. Geophys. Res., 102, 247-261, doi:10.1029/96JD02514.

Scaife, A. A., N. Butchart, and C. D. Warner, 2000: Realistic quasibiennial oscillations in a simulation of the global climate. Geophys. Res. Lett., 27, 3481-3484, doi:10.1029/2000GL011625.

Schmidt, H., and Coauthors, 2012: Solar irradiance reduction to counteract radiative forcing from a quadrupling of $\mathrm{CO}_{2}$ : Climate responses simulated by four earth system models. Earth Syst. Dyn., 3, 63-78, doi:10.5194/esd-3-63-2012.
Schoeberl, M. R., A. R. Douglass, R. S. Stolarski, S. Pawson, S. E. Strahan, and W. Read, 2008: Comparison of lower stratospheric tropical mean vertical velocities. J. Geophys. Res., 113, D24109, doi:10.1029/2008JD010221.

Stevens, B., and Coauthors, 2013: The atmospheric component of the MPI-ESM: ECHAM6. J. Adv. Model. Earth Syst., 5, 146172, doi:10.1002/jame.20015.

Takahashi, M., 1999: Simulation of the quasi-biennial oscillation in a general circulation model. Geophys. Res. Lett., 26, 13071310, doi:10.1029/1999GL900188.

Taylor, K. E., R. J. Stouffer, and G. A. Meehl, 2012: An overview of CMIP5 and the experiment design. Bull. Amer. Meteor. Soc., 93, 485-498, doi:10.1175/BAMS-D-11-00094.1.

Tomassini, L., E. P. Gerber, M. P. Baldwin, F. Bunzel, and M. A. Giorgetta, 2012: The role of stratosphere-troposphere coupling in the occurrence of extreme winter cold spells over northern Europe. J. Adv. Model. Earth Syst., 4, M00A03, doi:10.1029/2012MS000177.

Watson, P. G., and L. J. Gray, 2014: How does the quasi-biennial oscillation affect the stratospheric polar vortex? J. Atmos. Sci., 71, 391-409, doi:10.1175/JAS-D-13-096.1.

Wheeler, M., and G. Kiladis, 1999: Convectively coupled equatorial waves: Analysis of clouds and temperature in the wavenumber-frequency domain. J. Atmos. Sci., 56, 374-399, doi:10.1175/1520-0469(1999)056<0374:CCEWAO>2.0.CO;2.

Xue, X.-H., H.-L. Liu, and X.-K. Dou, 2012: Parameterization of the inertial gravity waves and generation of the quasi-biennial oscillation. J. Geophys. Res., 117, D06103, doi:10.1029/ 2011JD016778.

Yang, G.-Y., B. J. Hoskins, and J. M. Slingo, 2011: Equatorial waves in opposite QBO phases. J. Atmos. Sci., 68, 839-862, doi:10.1175/2010JAS3514.1.

- _ — , and L. J. Gray, 2012: The influence of the QBO on the propagation of equatorial waves into the stratosphere. J. Atmos. Sci., 69, 2959-2982, doi:10.1175/JAS-D-11-0342.1.

Zhu, X., 1993: Radiative damping revisited: Parameterization of damping rate in the middle atmosphere. J. Atmos. Sci., 50, 3008-3021, doi:10.1175/1520-0469(1993)050<3008: RDRPOD>2.0.CO;2. 